Published in final edited form as:

J Pediatr Adolesc Gynecol. 2017 October ; 30(5): 520-534. doi:10.1016/j.jpag.2017.04.001.

\title{
Congenital Adrenal Hyperplasia
}

\author{
Selma Feldman Witchel, MD \\ Division of Pediatric Endocrinology, Department of Pediatrics, Children's Hospital of Pittsburgh of \\ UPMC, University of Pittsburgh
}

\begin{abstract}
The congenital adrenal hyperplasias (CAH) comprise a family of autosomal recessive disorders that disrupt adrenal steroidogenesis. The most common form is due to21-hydroxylase deficiency associated with mutations in the CYP21A2 gene which is located at chromosome $6 \mathrm{p} 21$. The clinical features associated with each disorder of adrenal steroidogenesis represent a clinical spectrum reflecting the consequences of the specific mutations. Treatment goals include normal linear growth velocity and "on-time" puberty in affected children. For adolescent and adult women, treatment goals include regularization of menses, prevention of progression of hirsutism, and preservation of fertility. For adolescent and adult men, prevention and early treatment of testicular adrenal rest tumors is beneficial. This article will review key aspects regarding pathophysiology, diagnosis, and treatment of $\mathrm{CAH}$.
\end{abstract}

\section{Keywords}

Congenital adrenal hyperplasia; CYP21A2; Ambiguous genitalia; Premature pubarche; Hyperandrogenism; Premature adrenarche

\section{Introduction}

The congenital adrenal hyperplasias (CAH) comprise a family of autosomal recessive disorders that disrupt adrenal steroidogenesis. Three specific enzyme deficiencies are associated with virilization of affected females. The most common form is 21-hydroxylase deficiency (21-OHD) due to mutations in the 21-hydroxylase (CYP21A2) gene. Other virilizing forms include $3 \beta$-hydroxysteroid dehydrogenase and $11 \beta$-hydroxylase deficiencies associated with mutations in the $3 \beta$-hydroxysteroid dehydrogenase (HSD3B2) and $11 \beta$ hydroxylase (CYP11B1) genes, respectively. Oxidoreductase deficiency (PORD), due to mutations in the cytochrome $\mathrm{P} 450$ oxidoreductase $(P O R)$ gene can result in virilization of affected female fetuses and under-virilization of affected male. $P O R$ encodes a flavoprotein

\footnotetext{
Address correspondence to: Selma Feldman Witchel, MD, Division of Pediatric Endocrinology, Department of Pediatrics, Children's Hospital of Pittsburgh of UPMC, 4401 Penn Avenue, Pittsburgh, PA 15224, Phone: 412-692-5170, Fax: 412-692-5834, selma.witchel@chp.edu.

Publisher's Disclaimer: This is a PDF file of an unedited manuscript that has been accepted for publication. As a service to our customers we are providing this early version of the manuscript. The manuscript will undergo copyediting, typesetting, and review of the resulting proof before it is published in its final citable form. Please note that during the production process errors may be discovered which could affect the content, and all legal disclaimers that apply to the journal pertain.
} 
that serves as an electron donor for cytochrome P450 steroidogenic enzymes such as 21hydroxylase. Most of this review will pertain to 21-OHD.

In 1865, Luigi de Crecchio, a Neapolitan anatomist, reported the earliest documented description of a patient presumed to have 21-hydroxylase deficiency. At autopsy, the cadaver was described as having labioscrotal fusion, a $10 \mathrm{~cm}$ curved phallus with hypospadias, bilateral undescended testes, a vagina, a uterus, fallopian tubes, ovaries, and markedly enlarged adrenal glands. This individual had ambiguous genitalia at birth, reportedly presented as a male throughout his adult life, and presumably died of adrenal insufficiency in his 40s during an episode of vomiting, diarrhea, and prostration. ${ }^{1}$ Just over 100 years later in 1957, the nonclassic or mild form of 21-hydroxylase deficiency was described by Jacques Decourt, Max-Fernand Jayle, and Ettiene Baulieu. ${ }^{2}$

The features associated with $\mathrm{CAH}$ comprise a clinical spectrum reflecting the consequences of the specific mutation. In the case of 21-OHD, the continuum ranges from salt-losing and simple virilizing forms to the mild form. Collectively, the salt-losing and simple virilizing forms are considered to be the classic forms. The mild form is also known as the late-onset or non-classic form (NCAH). However, this classification system is somewhat artificial because disease severity is better represented as a continuum based on residual enzyme activity. The incidence of the classic forms is reported to range from 1:5000 to 1:15,000 and varies among ethnic/racial backgrounds. ${ }^{3}$ Ethnic specific mutations have been reported amongst Ashkenazi Jews, Iranians, Yupik-speaking Eskimos and East Indians. ${ }^{4}$

Additionally, the prevalence of 21-OHD is lower among African-Americans than Caucasians in the United States. ${ }^{5}$ Screening of 2 million newborns in New York State detected 105 confirmed cases of classical CAH; the incidence was approximately 1:15,500 for Asians and white infants, 1:17,450 for Hispanic, and 1: 24,840 for black infants. ${ }^{6}$ Incomplete ascertainment confounds accurate determination of the incidence of NCAH. However, available data indicate that $\mathrm{NCAH}$ is more common than the classic forms with an incidence of 1:1000 and increased prevalence among Hispanics, Yugoslavs, and Ashkenazi Jews. ${ }^{7}$

\section{Molecular Genetics}

The $C Y P 21 A 2$ gene is located in a complex genetic region at chromosome $6 \mathrm{p} 21.3$ where it lies in close proximity to a highly homologous pseudogene, CYP21A1P. CYP21A2 and $C Y P 21 A 1 P$ are arranged in tandem repeats with the $C 4 A$ and $C 4 B$ genes, which encode complement 4 (Figure 1). The tenascin $(T N X)$ and serine threonine nuclear protein kinase $(R P)$ genes are also mapped to this region. These four genes, $R P, C 4, C Y P 21$, and $T N X$, form a unit known as RCCX. Most alleles carry two RCCX units in which one has $C Y P 21 A 2$ and the other has $C Y P 21 A 1 P$.

To date, over 200 CYP21A2 mutations have been reported (http://www.hgmd.cf.ac.uk; www.cypalleles.ki.se). ${ }^{8}$ Yet, despite the large number of reported mutations, approximately 10 mutations account for the majority of affected alleles. Most mutations result from gene conversion events. Gene conversion events take place during meiosis when homologous recombination between the functional gene and the pseudogene results in a mismatch in base pairing. ${ }^{9}$ During this process, the functional gene can acquire deleterious $C Y P 21 A 1 P$ 
sequences or misalignment during meiosis can give rise to duplications or deletions of the RCCX unit. Haplotypes with 3 or 4 RCCX units have been described. ${ }^{10}$ Another example of misalignment is a $C Y P 21 A 1 P / C Y P 21 A 2$ chimera in which a portion of the $C Y P 21 A 1 P$ gene is fused to a portion of the $C Y P 21 A 2$ gene. ${ }^{11}$ Rarely, CAH can be associated with uniparental disomy. ${ }^{12}$ The de novo mutation rate is very low and is approximately $1 \%$.

Most affected individuals are compound heterozygotes with different mutations on each allele. Mutations range from complete loss of function to mild missense mutations. Estimates of in vitro 21-hydroxylase activity range from $<1 \%$ for mutations associated with salt-losing $\mathrm{CAH}$, to $2-10 \%$ for simple virilizing $\mathrm{CAH}$, and $30-50 \%$ for NCAH. An individual's phenotype generally reflects the residual enzyme activity of their milder mutation. Patients with classical salt-losing CAH usually carry complete loss of function mutations on both alleles. Patients with simple virilizing CAH typically have a complete loss of function mutation on one allele and the I172N or intron 2 splicing mutation on their other allele. Patients with NCAH often carry different mutations on each allele with at least one allele carrying a mild missense mutation such as V281L. Approximately $25-50 \%$ of individuals with NCAH are reported to have mild mutations on both alleles. ${ }^{13,14,15}$ Mutations associated with NCAH include V281L, P453S, and R339H. The P30L mutation is often detected in patients with $\mathrm{NCAH}$, but is typically associated with more severe androgen excess. ${ }^{16}$

\section{Pathophysiology}

The hypothalamic-pituitary-adrenal axis (HPA) regulates cortisol secretion by the adrenal cortex. The hypothalamus produces corticotrophin releasing hormone (CRH) which regulates the release of pituitary adrenocorticotropic hormone (ACTH). ACTH subsequently stimulates the adrenal cortex. Cortisol secretion by the adrenal gland, in turn "feeds back" to the hypothalamus to regulate $\mathrm{CRH}$ and $\mathrm{ACTH}$ production. Within the adrenal gland, the classical pathway begins with conversion of cholesterol to pregnenolone by the $\mathrm{P} 450$ side chain cleavage enzyme, encoded by CYP11A1 (Figure 2). Most steroidogenic enzymes are cytochrome P450 enzymes. This designation or family name is based on light absorbance at the $450 \mathrm{~nm}$ wavelength when reduced with carbon monoxide. ${ }^{17}$

Steroidogenesis in the adrenal gland is compartmentalized within the 3 zones of the adrenal cortex: the zona glomerulosa, zona fasciculata, and zona reticularis. In the zona glomerulosa, pregnenolone is converted to progesterone by $3 \beta$-hydroxysteroid dehydrogenase type 2 encoded by $H S D 3 B 2$. Progesterone is converted to dexoxycorticosterone by 21-hydroxylase encoded by $C Y P 21 A 2$ and subsequently to aldosterone by aldosterone synthase encoded by $C Y P 11 B 2$. Aldosterone secretion is regulated by the renin-angiotensin system and serum potassium concentrations.

In the zona fasciculata, pregnenolone is hydroxylated by the enzyme 17a-hydroxylase/ 17,20-lyase encoded by CYP17A1 to 17-hydroxypregnenolone, which is converted to 17hydroxyprogesterone (17-OHP) by $3 \beta$-hydroxysteroid dehydrogenase type 2 . Subsequently, 17-OHP is converted by 21 -hydroxylase to 11 -deoxycortisol, which is then converted by $11 \beta$-hydroxylase to cortisol. In the zona reticularis, the enzyme $17 a$-hydroxylase/17,20- 
lyase converts 17-hydroxypregnenolone to dehydroepiandrosterone (DHEA), which is subsequently converted to androstenedione by $3 \beta$-hydroxysteroid dehydrogenase type 2 . DHEA can undergo sulfation by steroid sulfotransferase, SULT2A1, to form DHEAS.

In the virilizing congenital adrenal hyperplasias, impaired cortisol synthesis leads to loss of cortisol negative feedback inhibition, increased hypothalamic corticotrophin releasing hormone (CRH), and increased pituitary adrenocorticotropic hormone (ACTH) secretion. The excessive ACTH secretion results in accumulation of steroid hormone intermediates proximal to the deficient enzyme and hyperplasia of the zona fasciculata and zona reticularis. Altered metabolism of these steroid hormone intermediates contributes to the hyperandrogenic elements associated with these enzyme deficiency disorders.

Decreased 21-hydroxylase enzymatic activity impairs cortisol biosynthesis with consequent increased 17-hydroxyprogesterone (17-OHP) and progesterone concentrations. The consequences of cortisol deficiency include poor cardiac function, poor vascular response to catecholamines, and increased secretion of anti-diuretic hormone. ${ }^{18}$ Complete loss of function mutations interfere with aldosterone synthesis leading to hyponatremia due to impaired urinary sodium reabsorption. The hyponatremia leads to hypovolemia, elevated plasma renin levels, and, eventually, shock if not promptly recognized and treated. In the absence of aldosterone, potassium cannot be excreted efficiently resulting in hyperkalemia. ${ }^{19}$ The elevated 17-OHP and progesterone concentrations exacerbate the mineralocorticoid deficiency because both hormones have anti-mineralocorticoid effects and, in vitro, interfere with aldosterone-mediated mineralocorticoid receptor transactivation. ${ }^{20}$ In addition, the lack of prenatal cortisol exposure interferes with adrenomedullary development and can be associated with epinephrine deficiency and hypoglycemia. $^{21}$

As noted above, in CAH due to 21-hydroxylase deficiency, the concentrations of the substrates immediately proximal to 21-hydroxylase, progesterone and 17-OHP are elevated. The phenotypic heterogeneity of CAH is more complex than would be anticipated for an autosomal recessive disorder in which the expression of the defective protein is limited to the adrenal cortex. This complexity is likely due to genetic variants at other loci, e,g, androgen receptor, that influence steroid metabolism and steroid responsiveness. Another factor influencing clinical features is the increased flux through the alternative or "backdoor" pathway for steroidogenesis which can exacerbate symptoms associated with androgen excess because of increased concentrations of DHT and other bioactive C-19 steroids.

In the alternative pathway, $17-\mathrm{OHP}$ is sequentially converted by $5 a$-reductase and the $3 a-$ reductase activities of AKR1C2/4 to generate 5a-pregnane-3a,17a-diol-20-one (pdiol) that is subsequently converted to dihydrotestosterone (DHT). ${ }^{22}$ This alternative pathway bypasses testosterone as an intermediate. Urinary concentrations of metabolites indicative of increased flux through the alternative pathway are higher in affected individuals, particularly infants. ${ }^{23}$ This pathway likely contributes to the androgen excess responsible for prenatal virilization of affected female fetuses. ${ }^{24}$ 
Under normal circumstances, the direct conversion of 17-OHP to androstenedione is not significant in humans. Yet, when 17-OHP accumulates in 21-OHD or PORD, it is metabolized by this alternative pathway. ${ }^{25}$ Defective 21-OHD also promotes accumulation of other steroid hormone intermediates such as 21-deoxycortisol and 16ahydroxyprogesterone, 11-ketoandrostenedione, and 11-ketotestosterone. ${ }^{26}$ It has been suggested that 11 -hydroxyandrostenedione (11OHAD), 11-ketoandrostenedione (11KAD), $11 \beta$-hydroxytestosterone (11OHT), and 11-ketotestosterone (11KT) are specific markers for adrenal-derived C-19 bioactive androgen hormones; both $11 \mathrm{KT}$ and $11 \mathrm{OHT}$ are able to signal through the androgen receptor. ${ }^{27,28}$

\section{Clinical features by Age}

\section{Infants}

Classic CAH presents in the neonatal period; the presentations differ depending on the sex of the affected infant. Diagnosis of salt-losing CAH is a medical emergency because of the risk for hyponatremia, hyperkalemia, hypotension, and potential fatal outcome within the first 2-3 weeks of life if not recognized. In addition, the extent of prenatal virilization can lead to mis-assignment of sex at birth. Hence, a possible diagnosis of 21-OHD needs to be promptly investigated and verified.

Infant females with classical CAH, either salt-losing or simple virilizing, generally present in the neonatal period with ambiguous genitalia. In some instances, the diagnosis of genital ambiguity has been suspected based on prenatal ultrasound findings. For affected female infants, the external genital findings can range from a nearly male appearance with penile urethra and bilateral undescended testes to minimal clitoromegaly. The most common physical findings in affected girls include clitoromegaly, fused rugated labia majora, and a single perineal orifice. Occasionally, the minimally virilized girl may not be identified until progressive clitoromegaly prompts a medical evaluation.

Apart from hyperpigmentation, external genital development is normal in affected males. Whereas girls are usually detected due to genital ambiguity, boys with salt-losing CAH appear well in the immediate newborn period. Infants with CAH tend to feed poorly and fail to regain their birthweight. Typically, they develop vomiting, hypotension, hyponatremia, and hyperkalemia in the first 10-14 days of life. Prior to implementation of newborn screening, affected boys typically presented with hyponatremic dehydration, hyperkalemia, and shock. Failure to make a timely diagnosis has led to fatal outcomes for affected males.

Affected 46,XX female infants have normal female internal genitalia. The uterus can be identified on ultrasound. The ovaries may be too small to be visualized on ultrasound. Despite excessive prenatal androgen exposure, ovarian position is normal, Mullerian structures persist, and the Wolffian ducts regress. The Mullerian structures develop normally as the fallopian tubes, uterus, and upper vagina. Virilized girls may have incomplete separation of the urethra and vagina resulting in a urogenital sinus and a single perineal orifice. The location at which the vagina enters the urethra varies from a high subvesical position to near the perineum. Cystoscopy, genitoscopy/vaginoscopy, perineal ultrasound, or MR imaging may be needed to accurately define the urogenital anatomy. ${ }^{29}$ 
Thus, when evaluating an infant with ambiguous genitalia, important features include symmetry of the external genital structures, presence and location of palpable gonads, appearance of the phallus including the extent of erectile tissue, genital skin pigmentation, extent of labioscrotal fusion, location and number of perineal openings, and the presence of additional anomalies. Importantly, the extent of external genital virilization is a manifestation of prenatal androgen exposure and degree of androgen sensitivity rather than chromosomal sex.

\section{Children}

Both male and female children with NCAH or simple virilizing CAH can present with premature development of pubic hair (premature pubarche). Premature pubarche is defined as the presence of pubic hair, axillary hair, or apocrine odor developing before 8 years in girls and 9 years in boys. Additional features in children include tall stature, accelerated linear growth velocity, and advanced skeletal maturation. Clitoromegaly may develop in girls. Boys manifest phallic enlargement with prepubertal-sized testes. In a multi-center study of 220 women with $\mathrm{NCAH}$, premature pubarche was the most common presenting feature in the 25 children less than 10 years of age; premature pubarche occurred in $10.5 \%$ of this group. ${ }^{30}$ Nevertheless, $\mathrm{CAH}$ is an uncommon cause of premature adrenarche. ${ }^{31}$ Among children with premature pubarche, the diagnosis of CAH can be suspected when basal 17-OHP, androstenedione, and testosterone concentrations are elevated and/or bone age is advanced. ${ }^{32}$ Although a cut-point of basal 17-OHP value $>200 \mathrm{ng} / \mathrm{dl}$ has been suggested, some patients with non-classic CAH may be overlooked using this value. ${ }^{28}$

\section{Adolescents and Adults}

Symptoms of NCAH include hirsutism, irregular menses, chronic anovulation, acne, and infertility. Hirsutism has been reported to be the most common presenting feature. ${ }^{33,34}$ These symptoms result in an ascertainment bias favoring diagnosis in affected women. Men with NCAH are typically identified through family studies. Individuals with NCAH usually do not have elevated ACTH concentrations. Some individuals demonstrate an exaggerated ACTH-stimulated glucocorticoid response, possibly reflective of subtle adrenal hyperplasia. ${ }^{35}$

Due to the similar clinical features, it may be difficult to distinguish NCAH from polycystic ovary syndrome (PCOS). ${ }^{36,37}$ Women with $\mathrm{NCAH}$ tend to have higher 17-OHP and progesterone concentrations than women with PCOS. ${ }^{38}$ Insulin resistance, obesity, polycystic ovary morphology, and elevated $\mathrm{LH} / \mathrm{FSH}$ ratios tend to be more common among women with PCOS. However, none of these features clearly differentiate women with NCAH from those with PCOS. ${ }^{39}$ Anti-Mullerian hormone concentrations do not discriminate women with NCAH from those with PCOS. ${ }^{40}$

Family studies have demonstrated that not all individuals with genotypes consistent with NCAH develop symptoms of androgen excess. Curiously, a study of 145 probands with CAH identified $4 \%$ of parents as having undiagnosed, also known as cryptic, NCAH. ${ }^{41}$ Apart from infertility among the women, these individuals had achieved normal adult heights and did not report symptoms indicative of episodes of adrenal insufficiency. 


\section{Presenting Clinical Features}

\section{Hirsutism}

Hirsutism is defined as excessive growth of coarse terminal hairs in androgen-dependent areas in women. Hirsutism reflects the apparent sensitivity of the pilosebaceous unit/hair follicle to both circulating androgen and local androgen concentrations. Importantly, the extent of the hirsutism correlates poorly with circulating androgen concentrations. ${ }^{42}$

Hair growth per unit skin area is similar in unselected white and black women. However, women from several Asian countries have been demonstrated to have less hair per unit skin area. ${ }^{43}$ The modified Ferriman-Gallwey scoring system (FG) provides a semi-subjective assessment of terminal hair growth in androgen-dependent body regions. This scoring system assesses hair growth using a scale from $0-4$ for nine body regions including mustache area, chin, upper chest, abdomen (upper and lower), upper back, lower back, upper arms, and thighs (Figure 3). To define hirsutism, one approach has been to utilize a FG score above the $95^{\text {th }}$ percentile for the population. Thus, hirsutism can be defined by FG scores $>8$ in premenopausal adult White and Black women, $\geq 9-10$ in Mediterranean, Hispanic, and Middle Eastern women, $\geq 2$ for Han Chinese women, and $\geq 5$ in Southern Chinese women. ${ }^{44,45}$ Nevertheless, modified FG scores $>3$ were uncommon among an unselected group of adult White and Black women. ${ }^{46}$

Hirsutism needs to be differentiated from hypertrichosis, which is characterized by excessive generalized hair growth. Familial factors, metabolic disorder, and certain medications, e.g. phenytoin, minoxidil, diazoxide, cyclosporine, and glucocorticoids, can be associated with hypertrichosis. Among women with seizure disorders, valproic acid treatment is associated with development of hyperandrogenism and cystic ovaries; this medication potentiates androgen biosynthesis in cultured human ovarian theca cells. ${ }^{47,48}$

\section{Hypothalamic-Pituitary-Ovarian (HPO) Axis}

Menstruation, Ovulation, and Reproduction-Oligomenorrhea, chronic anovulation, and infertility are common presenting complaints for women with NCAH and can occur in women with classic $\mathrm{CAH}$ despite adequate hormone replacement therapy. Women with CAH can develop a secondary "polycystic ovary syndrome" (PCOS) phenotype. ${ }^{49}$ PCOS is a clinical diagnosis based on oligomenorrhea associated with chronic anovulation, clinical or biochemical evidence of hyperandrogenism, and polycystic ovary morphology in the absence of any other disorder associated with androgen excess. ${ }^{50}$ The similarity in the features of PCOS and CAH suggest comparable mechanisms contribute to the HPO axis dysregulation in both disorders. In both disorders, bioactive C-19 androgens and progestins likely modulate HPO axis function through molecular mechanisms that have not yet been defined.

To briefly summarize, the hypothalamic GnRH neurons secrete $\mathrm{GnRH}$ in a pulsatile manner to stimulate pituitary LH and FSH secretion. Multiple neuroendocrine and environmental signals influence the function of the GnRH neurons. ${ }^{51} \mathrm{GnRH}$ pulse frequency is deciphered by the pituitary to generate preferential LH or FSH secretion. Indeed LH secretion has been used as a proximate indicator of GnRH pulses. LH and FSH stimulation of pre-ovulatory 
ovarian follicles leads to a steady increase in estradiol concentration. Although molecular mechanisms for the change in feedback mechanisms are unclear at present, the periovulatory elevation estradiol concentration triggers the change from negative to positive estrogen feedback. Positive estrogen feedback then culminates in the LH surge and ovulation. ${ }^{52}$ Subsequently, during the luteal phase of the menstrual cycle, progesterone mediated negative feedback decreases LH pulse frequency favoring FSH synthesis and perpetuation of menstrual cyclicity. ${ }^{53}$

Women with CAH can experience HPO axis dysfunction, which resembles PCOS. One mechanism postulated for the HPO axis dysfunction in CAH is that the excessive in utero androgen exposure alters imprinting of the neuroendocrine mechanisms that govern kisspeptin and GnRH neurons. ${ }^{54,55}$ The observation that prenatal androgen treatment recapitulates a PCOS phenotype in non-human primates, sheep, and rodents supports this hypothesis. ${ }^{56}$ Additional studies of women with PCOS may illuminate the interrelationships between gonadotropin secretion, androgens, ovarian function, and progesterone during androgen excess. Women with PCOS manifest increased LH concentrations, increased LH pulse frequency, increased LH pulse amplitude, and increased LH/FSH ratios. ${ }^{57}$ Additional data suggesting that androgen excess contributes directly or indirectly to increased LH pulse frequency is that exogenous testosterone treatment administered during puberty to nonhuman primates was associated with increased LH pulse frequency. ${ }^{58}$ Excessive androgen concentrations among women with NCAH have been associated with elevated LH concentrations and increased LH pulse amplitude. ${ }^{59}$

In a study of 16 women with classic $\mathrm{CAH}$ and 16 controls, Bachelot et al. identified two distinct patterns of $\mathrm{LH}$ secretion. Among women with $\mathrm{CAH}$ with appropriate hormone replacement as indicated by normal 17-OHP and androgen concentrations, LH concentrations and pulse frequency were similar to the control women. Decreased LH pulse amplitude and pulse frequency were found among the women with increased 17-OHP, progesterone, testosterone, and androstenedione concentrations. ${ }^{60}$ Since progesterone is known to decrease LH pulse frequency by actions at both the hypothalamus and the pituitary, the finding of hypothalamic hypogonadism is the context of elevated adrenal progesterone secretion is not surprising. ${ }^{61,62}$ Another possible explanation is that the elevated androgens may increase GnRH pulse frequency to such an extent that the pituitary is unable to maintain a concordantly elevated pulse frequency. ${ }^{63}$

Androgens may also directly affect ovarian function. Elevated androgen concentrations, whether endogenous as in $\mathrm{CAH}$ or exogenous as in testosterone treatment of female to male transgendered individuals, are associated with development of polycystic ovary morphology. ${ }^{64,65}$ Androgen actions are mediated by androgen receptors (AR), which are expressed in the theca cells, granulosa cells, and oocytes. ${ }^{66}$ In addition to AR, androgen actions are mediated by non-genomic pathways. Based on studies using tissue specific androgen receptor knockout mice, it appears that androgens act through the androgen receptor to influence follicular growth during multiple stages of follicular development. ${ }^{67}$ Whereas androgens promote initial growth of small antral follicles, hyperandrogenism is associated with follicular arrest and failure to select a dominant follicle. ${ }^{68}$ Within the ovary, 
androgens may stimulate the extracellular matrix contributing to stromal hyperplasia and rigidity. Thus, elevated androgens can disrupt the HPO axis at multiple points. ${ }^{69}$

\section{Acne and Alopecia}

Acne can occur among patients with NCAH and is rarely the primary clinical manifestation. Patients with severe cystic acne refractory to oral antibiotics and retinoic acid treatment should be evaluated for hyperandrogenism with NCAH being one cause for hyperandrogenism. Severe androgenic alopecia accompanied by marked virilization in older previously undiagnosed women has been described. ${ }^{70}$

\section{Diagnosis}

\section{Laboratory Aspects of Diagnosis}

Clinicians depend on consistent validated hormone determinations to confirm the diagnosis of disorder of steroidogenesis. Bioassays were followed by the development of immunoassays in which small molecules were covalently linked to immunogenic proteins that elicited antibodies directed to epitopes of the target steroid molecule. However, immunoassays, particularly free testosterone assays, lack adequate sensitivity to accurately measure low hormone concentrations. More robust mass spectrometry methods are increasingly available for commercial use. When performed by skilled personnel, liquid chromatography/tandem mass spectrometry (LC-MS/MS) provides an automated, or semiautomated, sensitive, and accurate assay of multiple steroids in small sample volumes. ${ }^{71}$ Urine gas chromatography mass spectrometry (GC/MS) is a lower throughput method, but has played a major role in the discovery of novel compounds and characterization of steroid pathways. $^{72}$

The diagnosis of salt-losing $\mathrm{CAH}$ should be considered for infants with ambiguous external genitalia and bilateral non-palpable gonads or with positive newborn screening test results. In these situations, electrolyte concentrations, plasma renin activity as well as 17-OHP, androstenedione, and progesterone determinations should be obtained emergently because of the high risk for hypotension, weight loss, and fatal outcome during the first 2-3 weeks of life for undiagnosed affected infants. An elevated 17-OHP concentration provides confirmation of the diagnosis of 21-hydroxylase deficiency. Most affected infants have random 17-OHP values $>5000 \mathrm{ng} / \mathrm{dl} .{ }^{73}$ Chromosome analyses and pelvic ultrasounds are recommended for virilized female infants to confirm an XX karyotype and the presence of a uterus.

For children with symptoms suggestive of NCAH, early morning basal 17-OHP values have been suggested as an effective screening test. Armengaud et al. reported $100 \%$ sensitivity and $99 \%$ specificity with a threshold value of $200 \mathrm{ng} / \mathrm{dl}(6 \mathrm{nmol} / \mathrm{L})$ to diagnose NCAH in children with premature pubarche. ${ }^{28} \mathrm{~A}$ bone age X-ray (X-ray of left hand) should be obtained to assess for acceleration of skeletal maturation. Similarly, early morning blood samples for 17-OHP determinations should be obtained in the follicular phase for reproductive aged cycling women. In this situation, Escobar-Morreale et al recommended using a basal $17-\mathrm{OHP}$ of $170 \mathrm{ng} / \mathrm{dl}(5.1 \mathrm{nmol} / \mathrm{L})$ as the cut-point for women. ${ }^{74}$ Changes in 
daily saliva 17-OHP concentrations better reflect ovarian function than adrenal function. ${ }^{75}$ Progestational activity of the corpus luteum may result in false positive results if 17-OHP concentrations are evaluated in the luteal phase.

Nevertheless, for any age group, an ACTH stimulation test may be warranted to complete the evaluation for $\mathrm{CAH}$. For an ACTH stimulation test, following collection of a basal blood sample, $0.25 \mathrm{mg}$ synthetic ACTH (Cortrosyn) is administered by intravenous or intramuscular routes; a second blood sample is collected at 30 and/or 60 minutes. Either 30 or 60 minute ACTH-stimulated 17-OHP levels can be used; the choice depends on physician preference. An ACTH-stimulated cortisol response $>18 \mathrm{mcg} / \mathrm{dl}$ is considered to indicate normal HPA axis function. ${ }^{76,77}$ In addition to 17-OHP, cortisol should be measured especially among individuals with NCAH to assess the adequacy of cortisol secretion. To differentiate 21-OHD from other disorders of steroidogenesis, determination of progesterone, 17-hydroxypregnenolone, 11-deoxycortisol, DHEA, deoxycorticosterone, and androstenedione may be warranted. ${ }^{78}$

CAH is an autosomal recessive disorder, which means that mutations should be detected on both $C Y P 21 A 2$ alleles. Based on the evaluation of women with NCAH, CYP21A2 mutations will likely be identified on both alleles when ACTH-stimulated 17-OHP concentrations are greater than $1500 \mathrm{ng} / \mathrm{dl}(45 \mathrm{nmol} / \mathrm{L})$. However, some individuals with diagnostic genotypes have ACTH-stimulated 17-OHP values between 1000-1400 ng/dl (30$45 \mathrm{nmol} / \mathrm{L}){ }^{79}$ These patients may benefit from additional laboratory evaluation; however caution should be used due to lack of widespread availability and standardization. The altered flux in the adrenal steroidogenic pathway leads to elevated 21-deoxycortisol, and 16a-hydroxyprogesterone concentrations ${ }^{80}$ Currently, commercial availability of assays for these hormones is limited. However, LC-MS/MS determination of these steroids is a sensitive and specific biomarker that will likely become clinically useful in the future.

\section{Genetic Aspects of Diagnosis}

As noted above, the complexity of the $C Y P 21 A 2$ locus precludes the use of genetic analysis as the first line diagnostic test. Most patients are compound heterozygotes and carry different mutations on each allele. In addition, identification of two mutations is not always diagnostic of CAH because multiple mutations may occur on the same allele (cis). ${ }^{10,81,82}$ Thus, multiple genetic testing strategies such as PCR-based mutation detection methods, sequencing, and multiplex ligation-dependent probe amplification may be needed to accurately segregate the mutations and ascertain RCCX unit copy number in an affected individual. ${ }^{83}$ In some instances, it may be necessary to perform genetic analyses on the parents to segregate the specific maternal and paternal mutations and confirm that mutations are on opposite alleles (trans). Nevertheless, genetic analysis can be a useful adjunct to newborn screening. ${ }^{84}$ Newer technologies, such as preimplantation genetic diagnosis of embryos conceived through in vitro fertilization or prenatal testing of cell-free DNA, may offer earlier diagnostic options. ${ }^{85}$ Reproductive-aged patients with CAH or NCAH should be offered genetic counseling to consider these options prior to conception.

J Pediatr Adolesc Gynecol. Author manuscript; available in PMC 2018 October 01. 


\section{Recurrence Risk}

The recurrence risk is $25 \%$ for each full sibling of the proband because 21-hydroxylase deficient CAH is an autosomal recessive disorder. Thus, siblings of the proband, especially those with $\mathrm{NCAH}$, may benefit from diagnostic evaluation. For women with $\mathrm{CAH}$, the risk of having a child with salt-losing or simple virilizing classical forms of CAH depends on the mother's genotype and the probability that the father is a carrier. In the situation of one parent having $\mathrm{CAH}$, molecular genetic analysis should be offered to the other parent particularly because available data suggest that that the incidence of CAH is more common than anticipated likely due to increased prevalence of $C Y P 21 A 2$ mutations in some ethnic groups. ${ }^{33}$ Whereas an ACTH-stimulated17-OHP concentration less than $400 \mathrm{mg} / \mathrm{dl}$ is reassuring that the person is not a carrier, molecular genetic testing may be needed to completely exclude carrier status. ${ }^{86}$

\section{Newborn Screening}

Newborn screening (NBS) for CAH was initiated in late 1970's using filter paper whole blood 17-OHP measurements of whole blood 17-OHP. ${ }^{87}$ All 50 states and many countries have developed NBS programs. ${ }^{88}$ The major goal of NBS is to identify infants with saltlosing and simple virilizing CAH and to prevent mis-identification of affected females. NBS programs have decreased the morbidity and mortality associated with acute adrenal insufficiency. The screening algorithm includes collection of heel-stick blood sample onto a filter paper. Whole blood 17-OHP concentration is typically determined using automated time-resolved-dissociation-enhanced lanthanide fluoroimmunoassay (DELFIA).

The reported false positive rates for CAH vary from $0.4-9.3 \% .{ }^{89}$ Most false positive screening results are associated with prematurity, low birthweight, neonatal stress, methodological, or technical issues. Decreased $11 \beta$-hydroxylase activity in the neonate appears to be another factor contributing to false positive testing..$^{90}$ In addition, crossreactivity with sulfated steroids and 16a-hydroxyprogesterone contributes to false positive results. To minimize false positive results, blood samples should be collected after 48 hours of life. ${ }^{91}$ Birthweight, gestational age, and collection age cut-points have been developed to minimize recalls for false positive tests.

False negative 17-OHP results leading to delayed or missed diagnoses have also been reported for both newborn girls and boys. ${ }^{92} \mathrm{~A}$ false negative rate of $22.4 \%$ was reported for Minnesota. ${ }^{93}$ Surprisingly. in a series of 234,793 infants from Wisconsin, 6 of 7 female infants with false negative NBS results had virilization of their external genitalia. ${ }^{94}$ Fewer cases are missed in states in which a second NBS is obtained at approximately 8-14 days of age. ${ }^{95,96}$ Currently, Arizona, California, Delaware, Nevada, New Mexico, Oregon, Texas, Utah, and Wyoming mandate a second NBS. ${ }^{97}$

\section{Treatment}

Upon confirming the diagnosis of classical salt-losing or simple virilizing 21-OHD, glucocorticoid and mineralocorticoid hormone replacement therapies need to be initiated. Although patients with simple virilizing 21-OHD are not overt salt-losers, they may benefit 
from mineralocorticoid replacement therapy. For patients with NCAH, treatment needs to be focused on the individual's symptoms and should not be initiated merely to decrease abnormally elevated hormone concentrations. ${ }^{98}$ For children and adolescents, treatment goals include normal linear growth velocity, normal rate of skeletal maturation, appropriately timed spontaneous pubertal development, and positive self-esteem. Treatment goals for adolescents and adult women include normal menstrual cyclicity, fertility, and prevention of further hirsutism and acne. If possible, care should be provided in a multidisciplinary setting. ${ }^{99}$

Laboratory surveillance includes assessing whether androstenedione and testosterone concentrations are appropriate for age and gender. The 17-OHP and progesterone concentrations may be elevated even in the presence of excessive glucocorticoid administration. ${ }^{100}$ Replacement therapy doses should not be based on 17-OHP concentrations because normalization of 17-OHP and progesterone concentrations generally indicates excessive glucocorticoid hormone replacement therapy. Dehydroepiandrosterone sulfate (DHEAS) concentrations are readily suppressed during treatment and cannot be used to assess the adequacy of replacement glucocorticoid therapy. ${ }^{101}$

Hydrocortisone (CortefR) is the preferred glucocorticoid replacement in infants, children, and adolescents. The usual dosage ranges from $6-15 \mathrm{mg} / \mathrm{m}^{2} /$ day generally administered three times per day. Some clinicians advocate reverse circadian dosing with the highest dose in the evening. Hydrocortisone dose equivalence greater than $17 \mathrm{mg} / \mathrm{m}^{2} /$ day during childhood was associated with greater compromise of adult height. ${ }^{102}$ Prednisone and dexamethasone have longer half-lives such that less frequent dosing is needed; these medications may be considered for use in the adult patient. Some adult patients are well controlled on combinations of hydrocortisone and small doses of prednisone or dexamethasone at bedtime. ${ }^{103}$

Mineralocorticoid replacement involves treatment with 9a-fludrocortisone acetate; the goal is to achieve plasma renin activity that is within normal limits for age. Due to their salt-poor diet, transient pseudo-hypoaldosteronism, and immature kidneys, infants typically require higher mineralocorticoid replacement doses during the first few months of life. Some infants may require additional salt supplementation. Monitoring of blood pressure to avoid hypertension and plasma renin activity are useful parameters to assess the adequacy of mineralocorticoid replacement therapy.

Stress dosing is necessary for significant illnesses, surgery, or life-threatening stress. Tripling the usual daily dose is the semi-arbitrary guideline for stress dosing. If the individual is unable to take or tolerate oral medications, parental hydrocortisone should be administered as follows: < 12 months of age, $25 \mathrm{mg}$; 1-4 years of age, $50 \mathrm{mg}$; > 4 years of age, $100 \mathrm{mg}$. The duration of action of IM parental hydrocortisone is approximately 4-6 hours. Typically, patients can tolerate subsequent oral doses. However, all patients require individualized therapy and some may require intravenous fluids. Stress dosing (triple dose) is often maintained for the duration of the acute illness. When the patient improves, doubling of the usual dose is generally done for one day before resumption of the patient's usual glucocorticoid dosage regimen. 
All individuals on glucocorticoid treatment require instruction regarding stress doses, administration of parental hydrocortisone, and should wear medical alert identification badges/jewelry. To assure patient safety and well-being, current recommendations are to provide glucocorticoid stress dose treatment to all with ACTH-stimulated cortisol responses $<18 \mathrm{mcg} / \mathrm{dl}$ during times of physiologic stress. ${ }^{104}$ Decisions regarding daily glucocorticoid replacement therapy when ACTH-stimulated cortisol response is $<18 \mathrm{mcg} / \mathrm{dl}$ must be individualized based on symptoms of androgen excess and glucocorticoid deficiency.

Treatment of CAH is often challenging because of the difficulties inherent in balancing overtreatment and undertreatment. Parameters that influence optimal dosing include variation in absorption from the gastrointestinal tract, corticosteroid binding globulin (CBG) concentrations, and cortisol half-life in the circulation. ${ }^{105}$ For this reason, novel therapies are being explored. One approach has been the development of a time released glucocorticoid preparation, ChronoCort. ${ }^{106}$ Continuous glucocorticoid replacement using a subcutaneous pump has been tried. ${ }^{107}$ Abiraterone acetate which inhibits CYP17A1 has been used in conjunction with simultaneous glucocorticoid and mineralocorticoid replacement therapy. ${ }^{108}$ Treatment of CAH may become increasingly problematic during adolescence due to increased cortisol clearance, decreased serum cortisol half-life, and increased CBG concentrations. ${ }^{109,110}$

Anti-androgens, e.g. flutamide, cyproterone acetate, or finasteride, may be considered for women complaining of excessive unwanted hair growth or androgenic alopecia.

Nevertheless, precautions should be taken due to the potential for severe adverse events associated with anti-androgen therapies. Patients with a history of hepatic disease or glucose-6-phosphate dehydrogenase (G6PD) deficiency should avoid use of flutamide due to concerns for hepatic failure and hemolytic anemia, respectively. In addition, use of antiandrogen therapies during pregnancy can lead to undervirilization of male fetuses.

\section{Transition to Adult Care}

Although transition can be compared to "graduation" from pediatrics to adult care, transition from pediatric to adult care involves a multi-step process. ${ }^{103}$ This process requires communication, education, and cooperation among patient, family members, and health care providers. Potential obstacles and challenges include the patient's comprehension of the pathophysiology of $\mathrm{CAH}$, continued access to experienced health care providers, the patient's willingness and ability to assume responsibility for self-care, and the parents' cooperation to empower the patient to make independent decisions. Unfortunately, some patients may have accumulated negative experiences due to multiple genital examinations, inadequate knowledge about $\mathrm{CAH}$, and stigmatization regarding their disorder; these patients may find it difficult to trust health care professionals. ${ }^{11,112}$

The process of transition begins during adolescence several years before the actual shift in health care situations occurs. During these years, adolescents tend to show increased risk taking behaviors characterized by a sense of invincibility, difficulty recognizing the consequences of their actions, experimentation with sex and recreational drugs, and poor adherences to recommended treatment regimens. Problem-solving discussions between the 
patient and the health care provider to identify creative solutions to improve adherence to the recommended regimen may be invaluable. As part of the transition process, the healthcare providers can address relevant concerns for the future. These concerns include appropriate individualized hormone replacement therapy, potential anatomic concerns for girls with $\mathrm{CAH}$, initial evaluation for testicular adrenal rest tumors (TARTs) in boys with $\mathrm{CAH}$, and the plan for the transition process. ${ }^{113}$ Systems issues such as inadequate health insurance coverage and incomplete communication between health care providers can complicate the transition process.

Throughout childhood, children and adolescents with CAH may have relied on their parents for decision-making during these developmental stages. The emerging adult with $\mathrm{CAH}$ needs to understand the pathophysiology of $\mathrm{CAH}$ including the rationale for hormone replacement therapy, genetic inheritance, fertility, sexuality, and possible long-term health consequences such as osteopenia. Provision of a checklist listing self-care milestones and a portal summary of the individual's medical record can help the adolescent assume responsibility for his/her medical care (Table 1).

\section{Sexuality}

The majority of women with CAH report heterosexual preferences. Although the exact frequency is unclear, up to $25 \%$ of women with $\mathrm{CAH}$ report homosexual inclinations when surveyed. ${ }^{114}$ Adult women with CAH manifest increased gender-atypical behavior regarding their choices for professional occupations, sporting interests, and spare time activities. The extent of the gender-atypical behavior was correlated with the severity of the CYP21A2 genotype. Additional potential consequences of prenatal androgen exposure on the developing female brain are being explored. ${ }^{115}$ These data affirm prenatal androgen organizational effects of on brain development. ${ }^{116}$

Sexual debut tends to occur at older ages for girls with CAH. ${ }^{117}$ For women with classical $\mathrm{CAH}$, additional issues related to sexual experiences and sexual activity include small vaginal introitus, lack of lubrication, pain with penetration, lack of clitoral sensitivity, and anxieties about sexual performance and genital appearance..$^{90,118}$ In one series, women with $\mathrm{CAH}$ reported later sexual debut, fewer pregnancies and children, and increased incidence of homosexuality which were related to type of surgical correction and the severity of their mutations. ${ }^{119}$ Medical secrecy, embarrassment about atypical genital appearance, and confusion regarding genital appearance and concepts regarding gender identity further confound patient-physician conversations.

Infant girls with genital ambiguity may undergo feminizing genitoplasty surgery during the first year of life. To reduce scarring, this operation is preferably performed in the first few months when the infant's skin is still estrogenized. ${ }^{120}$ Feminizing genitoplasty involves opening the vaginal introitus, bringing the urethral meatus closer to the perineum, and reducing the size of an enlarged clitoris. A major surgical objective is to preserve the glans and neurovascular bundle to minimize loss of sensation. Additional goals of surgery include allowing for menstrual flow, enabling tampon use and vaginal intercourse, and preventing urinary tract infections. ${ }^{121}$ Surgical techniques have changed over the years. The specific 
procedure utilized for vaginoplasty depends on the point of entry of the vagina into the urogenital sinus and extent of virilization. For some girls, a second stage vaginoplasty operation during adolescence or vaginal dilation may be beneficial.

Several reports regarding XX individuals raised as males have indicated well-established male gender identities and gender role. With parental support and appropriate endocrine management, outcomes have been positive. ${ }^{122}$

\section{Contraception, Fertility and Pregnancy}

In addition to concerns regarding sexuality, women with CAH and NCAH may experience difficulty in achieving pregnancy. ${ }^{123}$ Similarly, irregular menses and anovulatory cycles may lead female patients to infer that contraception is unnecessary. Thus reproductive counseling should include discussion regarding goals for family planning. Although anovulatory cycles will not result in conception, female patients with $\mathrm{CAH}$ and $\mathrm{NCAH}$ are indeed fertile and should be offered contraception if sexually active without a desire to conceive. Persistent anovulatory cyles may be managed with combined oral contraceptives or long-active hormonal contraception such as an progestin-only intrauterine device or implant.

In the past, infertility was the anticipated outcome for women with classic CAH. ${ }^{124}$ Improved pregnancy rates have been reported, but factors contributing to the lack of fecundity include vaginal stenosis with dyspareunia, impaired sensation, poor self-esteem, chronic anovulation, disinterest having children, and elevated progesterone concentrations. ${ }^{125}$

Fertility issues in $\mathrm{CAH}$ are not limited to females. Fertility may also be compromised in affected men because of TARTs. In addition, elevated adrenal C-19 bioactive steroid concentrations can lead to hypogonadotropic hypogonadism. Both TARTs and hypothalamic hypogonadism can lead to oligospermia. ${ }^{126}$ Testis-sparing surgery may decrease the size of the TART, but may not restore fertility. ${ }^{127}$

Excessive circulating androgen and progestin concentrations can affect HPO axis function and uterine receptivity. As noted above, elevated androgen concentrations may influence neuroendocrine regulation of $\mathrm{GnRH}$ and $\mathrm{LH}$ secretion. Elevated progesterone concentrations do not directly impact oocytes. Rather, elevated progesterone concentrations affect the quality of cervical mucus, decrease sperm penetration, accelerate endometrial maturation, diminish endometrial receptivity, and impair implantation. ${ }^{128}$ Adequate suppression of progesterone $(<60 \mathrm{ng} / \mathrm{dl})$ and plasma renin activity appears to be important for ovulation, endometrial proliferation, and implantation for both classic and NCAH. With optimization of glucocorticoid and mineralocorticoid regimens, fewer patients with CAH require ovulation induction. Prior to the diagnosis of NCAH, the risk for early pregnancy loss is higher. Two studies of women with NCAH demonstrated decreased number of spontaneous miscarriages in women after diagnosis of $\mathrm{NCAH}$ and with use of glucocorticoid replacement therapy. ${ }^{33,34}$

Prior to pregnancy, women should be offered partner testing and genetic counseling regarding risk for offspring. Once pregnancy is achieved, women with CAH warrant 
individualized care through joint management with endocrinologists and obstetricians.

Women with CAH should be treated with steroids inactivated by the placenta to prevent fetal glucocorticoid exposure; doses may need to be increased slightly during pregnancy. The goal should be to maintain testosterone and androstenedione concentrations in the range found in normal pregnancies. Since gestational diabetes may be more frequent among pregnant women with $\mathrm{CAH}$, blood glucose should be monitored. For women who have undergone feminizing genitoplasty, delivery by Caesarean section is preferable for most women. Stress dose glucocorticoids should be started at the onset of labor and continued until after delivery. ${ }^{129}$

\section{Prenatal Dexamethasone Treatment}

Prenatal dexamethasone treatment has been used in the past to prevent or ameliorate the genital virilization of female infants with classical $\mathrm{CAH}$, with the goal of reducing the need for feminizing genital reconstructive surgery. ${ }^{130}$ Under normal circumstances, the human fetal adrenal cortex does not synthesize significant quantities of cortisol during early pregnancy. ${ }^{131}$ The fetus is protected from maternal glucocorticoids by placental expression of the $11 \beta$-hydroxysteroid dehydrogenase type 2 (HSD11B2) enzyme that inactivates maternal cortisol by converting it to inactive cortisone. In addition, the placenta expresses aromatase, which converts androgens to estrogens to minimize fetal exposure to maternal androgens. ${ }^{132}$ In one series early administration of dexamethasone reduced virilization scores however, the treatment is not without fetal risk. ${ }^{133}$

Because fetal genital virilization begins 6-7 weeks after conception, treatment must be started as soon as the woman knows she is pregnant. Hence, for prenatal dexamethasone to be efficacious, all pregnancies deemed to be at risk for virilizing $\mathrm{CAH}$ need to be treated, even though only 1 in 8 fetuses is predicted to be an affected female with CAH. As dexamethasone is about 50-80 times more potent than cortisol (hydrocortisone) and can cross the placenta, infants treated with prenatal dexamethasone receive approximately 60 times the usual, physiologic glucocorticoid exposure.

It has been suggested that the use of maternal cell-free DNA to identify the SRY gene accompanied by sequencing of the CYP21A2 gene will identify affected females and limit exposure of unaffected and male fetuses. ${ }^{134}$ However, the use of maternal cell-free DNA is limited due to the possibility for false negative/positive results and the need for a quick turnaround time. Chorionic villus sampling and amniocentesis may be pursued in the first and second trimester, respectively. Another option is preimplantation genetic diagnosis (PGD), which allows selection of unaffected embryos. PGD requires genetic screening of parents to identify specific mutations for probe design. It also requires in vitro fertilization (IVF) for embryo development. PGD is rarely covered by health insurance and may be costprohibitive for most couples. ${ }^{135}$

Although prenatal dexamethasone appears to decrease virilization of the female fetus, birthweights of treated infants are lower than control infants. ${ }^{136}$ Outcome studies in humans have demonstrated structural changes in the brain. Specifically, prenatal glucocorticoid exposure has been associated with cortical thinning in the rostral anterior cingulate cortex 
and neuropsychiatric changes. ${ }^{137,138}$ Using standardized neuropsychological tests and questionnaires, early prenatal dexamethasone treatment of pregnancies at risk for $\mathrm{CAH}$ was demonstrated to negatively impact cognitive functions of the healthy unaffected girls who not benefit from this treatment. ${ }^{139}$ Animal and in vitro studies raise additional safety concerns regarding prenatal dexamethasone exposure. ${ }^{140}$ Glucocorticoids influence normal neuronal development because of their role in terminal maturation and cell survival. Prenatal dexamethasone treatment of primary murine fetal neural stem/progenitor cell (NSPC) cultures alters the developmental trajectory of the developing neural tissue. ${ }^{141}$

Available data regarding clinical outcome studies and using animal models raise significant concern about the use of prenatal dexamethasone treatment and urge that it not be used except in research studies under the guidance of the appropriate Institutional Review Board. ${ }^{140,142}$

\section{Outcome Data and Potential Sequelae Associated with CAH}

With improvements in treatment, more children with $\mathrm{CAH}$ are transitioning to adulthood. Available outcome studies are disappointing, but it must be remembered that the standard management for $\mathrm{CAH}$ was different 20-40 years ago. Many patients appear to be lost to follow-up medical care. Outcome studies from the UK and the USA have reported that obesity, adverse metabolic profile, and osteopenia were common. ${ }^{143,144}$ There are no apparent correlations between genotype and outcome. ${ }^{145}$ Short stature, metabolic syndrome, hypertension and adverse cardiovascular risk have been inconsistently noted. ${ }^{146,147,148} \mathrm{~A}$ single center French study also reported that overweight/obesity, abnormal bone mineral density, irregular menses, hirsutism, adrenal hyperplasia/adrenal nodules, and testicular adrenal rest tumors were common in their adult patients with CAH; with the exception of TARTs, the undesirable outcomes were associated with inadequate disease control as assessed by longitudinal hormone determinations. ${ }^{149}$ A Swedish cohort study reported that psychiatric diagnoses and substance abuse were more common among women with $\mathrm{CAH}$ compared to controls. The reasons for this disparity await clarification. ${ }^{150}$

\section{Precocious Puberty}

Precocious puberty, both GnRH-independent and GnRH-dependent have been described in association with $\mathrm{CAH}$. In patients with $\mathrm{CAH}$, peripheral elevations of androgens may result in early development of apocrine body odor, pubic hair, axillary hair, and acne. Skeletal maturation is a particular challenge as excess androgens may result in advanced bone age; patients with extremely advanced skeletal maturation, i.e. greater than $2 \mathrm{SD}$ advanced, may benefit from hydrocortisone treatment.

A complication of delayed diagnosis and treatment of $\mathrm{CAH}$ with corticosteroids includes development GnRH-dependent precocious puberty. Although the underlying etiology is unclear, this premature activation of the GnRH pulse generate has also been associated with advanced skeletal maturation. Some children with secondary GnRH-dependent precocious puberty may benefit from treatment with leuprolide acetate or histrelin to suppress gonadotropin secretion. ${ }^{151,152,153}$ 


\section{Bone Health}

Chronic use of glucocorticoids has deleterious effects on bone health. ${ }^{154}$ Due to the requirement for chronic glucocorticoid replacement therapy, individuals with $\mathrm{CAH}$ experience a greater risk for decreased bone mineral density. Bone is comprised of three cell types: osteoblasts, osteocytes, and osteoclasts. Glucocorticoids influence all three cell types. Glucocorticoids decrease the number of osteoblasts by decreasing replication of osteoblastic precursors, redirecting differentiation of bone marrow stem cells to adipocyte cell lineages, and enhancing apoptosis. Glucocorticoids suppress the canonical Wnt- $\beta$-catenin signaling pathway and inhibit osteoblast differentiation by repressing bone morphogenetic protein 2 . Glucocorticoids appear to interfere with the biomechanical functions of osteocytes and promote increased bone resorption by osteoclasts. ${ }^{155}$ Falhammar et al. reported decreased bone mineral density in adult men with $\mathrm{CAH}$ compared to age-matched controls. ${ }^{156}$

Since DXA is based on a two-dimensional technique, interpretation of areal (grams per square centimeter) bone mineral density assessed by DXA scan can be confounded by bone width and height. Areal BMD assessment appears to provide better correlation with age than the more traditional volumetric density (grams per cubic centimeter). ${ }^{157}$ Thus, DXA can underestimate bone mineral density in shorter individuals. Available data, derived from outcome reports for individuals with classical $\mathrm{CAH}$, are inconsistent due to varying glucocorticoid doses, potential compliance issues, and subject heterogeneity. The most recent Endocrine Society Guidelines do not recommend routine DXA scans. ${ }^{142}$

\section{Adrenomedullary Function}

Glucocorticoids help organize adrenal medullary development during fetal life and induce the enzyme, phenylethanolamine $\mathrm{N}$-methyltransferase, which catalyzes the conversion of norepinephrine to epinephrine in the adrenal medulla. Adrenal medullary hypoplasia, impaired epinephrine secretion, and hypoglycemia have been reported among individuals with classical CAH. ${ }^{21,158}$

\section{Gonadal Rest Tumors}

Gonadal adrenal rest tumors, predominantly TARTs occur in up to half of men. These tumors arise from adrenal cells that descend with the testes during fetal testicular development. TARTs are not malignant, but can compress the rete testis and seminiferous tubules resulting in testicular atrophy and obstructive azoospermia. Ultrasound and MRI are helpful to detect TARTs especially because small lesions $(<2 \mathrm{~cm})$ are generally not palpable. TARTs may develop during childhood and adolescence and have rarely been described in men with nonclassic CAH. ${ }^{159,160}$ Although TARTs have been attributed to poor adherence to glucocorticoid replacement therapy, pathogenesis of TARTS may be more complicated. ${ }^{161}$ Periodic screening for TARTs is recommended to start during in adolescence. Ovarian adrenal rest tumors (OARTs) have been infrequently reported in affected women. ${ }^{162}$

\section{Adrenal Myelolipomas}

Adrenal myelolipomas are rare, but may develop in patients with CAH poorly adherent with steroidal treatment. Presenting features may include diffuse abdominal pain, nausea, and 
vomiting. ${ }^{163}$ Adrenal myelolipomas consist of myeloid, erythroid, and megakaryocytic cell lines and appear as hyperechoic masses on ultrasound and fat containing masses on CT scan. MRI signal characteristics depend on the composition of the lesion. Typically, these lesions are benign and contain hematopoietic tissue; larger lesions are at risk for hemorrhage or rupture. The masses may become quite large and require surgical excision due to spaceoccupying concerns.

\section{Other Defects in Steroidogenesis}

\section{Oxidoreductase Deficiency}

This flavoprotein serves as a mandatory electron donor for several steroidogenic enzymes including 7a-hydroxylase (CYP17A1), 21-hydroxylase (CYP21A2), and also P450 aromatase (CYP19A1). However, activities of these steroidogenic enzymes may be differentially affected by specific POR mutations. ${ }^{164}$ Generally, affected infants present in the newborn period. Clinical features include ambiguous genitalia, adrenal insufficiency, and skeletal anomalies. Affected females may develop large ovarian cysts prone to spontaneous rupture. ${ }^{165}$ The skeletal malformations include craniosynostosis, midface hypoplasia, and phalangeal anomalies. The skeletal malformations have been attributed to defective cholesterol biosynthesis due to effects of cytochrome $\mathrm{P} 450$ oxidoreductase $(P O R)$ gene mutations on cholesterol biosynthetic enzymes. ${ }^{166}$ Unlike 21-hydroxylase deficiency, postnatal virilization does not occur in this disorder. Rarely, females may present with infertility. ${ }^{167}$ Mineralocorticoid secretion is typically normal. Diagnosis can be made on ACTH stimulation tests with measurements of serum progesterone, 17hydroxypregnenolone, 17-OHP, cortisol, DHEA, and androstenedione or urine metabolites. ${ }^{168,169}$ The need for glucocorticoid replacement varies depending on ACTHstimulated cortisol response.

\section{3 $\beta$-Hydroxysteroid Dehydrogenase/Isomerase Type 2 Deficiency}

This disorder of steroidogenesis is due to mutations in the $3 \beta$-hydroxysteroid dehydrogenase/isomerase type 2 ( $H S D 3 B 2$ ) gene. Mutations in this gene affect both mineralocorticoid and glucocorticoid pathways by decreasing conversion of pregnenolone to progesterone and 17-hydroxypregnenolone to 17 -OHP, respectively. ${ }^{170}$ Mutations in the gene also interfere with steroid flux to androgens leading to testosterone deficiency with undervirilization of affected male infants. Yet, affected female infants can be mildly virilized due to the actions of the homologous HSD3B1 protein.

\section{1 $\beta$-Hydroxylase Deficiency}

This disorder of steroidogenesis is due to mutations in the $11 \beta$-hydroxylase gene encoded by CYP11B1. This enzyme deficiency impairs the conversion of 11-deoxycortisol to cortisol. Similar to 21-hydroxylase deficiency, the loss of negative feedback inhibition leads to increased production of bioactive adrenal C-19 steroid precursors. Due to increased deoxycorticosterone, these patients are frequently hypertensive and may have hypokalemia. Nonclassic forms have been described associated with androgen excess, premature pubarche, and hypertension. Timely diagnosis is helpful to minimize the co-morbidities associated with hypertension and androgen excess. ${ }^{171}$ 


\section{Lipoid Congenital Adrenal Hyperplasia}

This disorder is associated with mutations in the steroidogenic acute regulatory protein (StAR) gene. No adrenal or gonadal steroids can be synthesized. This disorder is characterized by massive lipid accumulation in the adrenal cortex. Affected females may experience thelarche and, possibly, menarche because the ovaries may retain sufficient steroid production capacity to allow for some estrogen biosynthesis at the time of puberty. Affected males are undervirilized. Both sexes typically present with life-threatening adrenal insufficiency in the newborn period. With ovulation induction and progesterone support, pregnancy can be achieved. ${ }^{172}$ Milder variants have been reported. ${ }^{173}$

\section{Cholesterol Desmolase Deficiency}

Initially, mutations in the cholesterol desmolase (CYP11A1) gene were considered to be incompatible with life due to decreased progesterone synthesis. The phenotype resembles congenital lipoid adrenal hyperplasia without the massively enlarged adrenal glands. Milder variants have been described. ${ }^{174}$

\section{7a-Hydroxylase/17,20-Lyase Deficiency}

This disorder is associated with mutations in the 17a-hydroxylase/17,20-lyase (CYP17A1) gene and leads to impaired glucocorticoid and sex steroid biosynthesis. These patients typically present with hypogonadism, hypertension, and hypokalemia. Basal LH and progesterone concentrations may be elevated. ${ }^{175}$

\section{Future Directions}

Evolving technologies offer the opportunity for prenatal and even preconception diagnosis of CAH. Although early diagnosis may be helpful for counseling of parents, with increasing awareness of the potential consequences of prenatal androgen exposure, continued discussions regarding gender of rearing for severely virilized females is warranted. Similarly, further studies regarding sexuality and quality of life measures are warranted for this population. Most importantly, novel therapeutic modalities such as modified release hydrocortisone preparation may provide better quality of life for patients with CAH. ${ }^{176}$

\section{References}

1. Delle Piane L, Rinaudo PF, Miller WL. 150 years of congenital adrenal hyperplasia: translation and commentary of De Crecchio's classic paper from 1865. Endocrinology. 2015; 156:1210. [PubMed: 25635623]

2. Decourt MJ, Jayle MF, Baulieu E. Virilisme cliniquement tardif avec excretion de pregnanetriol et insuffisance de la production du cortisol. Ann Endocrinol (Paris). 1957; 18:416. [PubMed: 13470408]

3. Thil'en A, Nordenstrom A, Hagenfeldt L, von Dobeln U, Guthenberg C, Larsson A. Benefits of neonatal screening for congenital adrenal hyperplasia (21-hydroxylase deficiency) in Sweden. Pediatrics. 1998; 101(4):E11.

4. Wilson RC, Nimkarn S, Dumic M, et al. Ethnic-specific distribution of mutations in 716 patients with congenital adrenal hyperplasia owing to 21-hydroxylase deficiency. Mol Genet Metab. 2007; 9:414. 
5. Therrell BL Jr, Berenbaum SA, Manter-Kapanke V, et al. Results of screening 1.9 million Texas newborns for 21-hydroxylase-deficient congenital adrenal hyperplasia. Pediatrics. 1998; 101(4 Pt 1):583. [PubMed: 9521938]

6. Pearce M, DeMartino L, McMahon R, et al. Newborn screening for congenital adrenal hyperplasia in New York State. Mol Genet Metab Rep. 2016; 7:1. [PubMed: 27331001]

7. Speiser PW, Dupont B, Rubinstein P, et al. High frequency of nonclassical steroid 21-hydroxylase deficiency. Am J Hum Genet. 1985; 37:650. [PubMed: 9556656]

8. Bruque CD, Delea M, Fernandez CS, et al. Structure-based activity prediction of CYP21A2 stability variants: A survey of available gene variations. Sci Rep. 2016 Dec 14.6:39082. [PubMed: 27966633]

9. Higashi Y, Tanae A, Inoue H, et al. Evidence for frequent gene conversion in the steroid 21hydroxylase P-450(C21) gene: implications for steroid 21-hydroxylase deficiency. Am J Hum Genet. 1988; 42:17. [PubMed: 2827462]

10. Parajes S, Quinteiro C, Dominguez F, et al. High frequency of copy number variations and sequence variants at CYP21A2 locus: implication for the genetic diagnosis of 21-hydroxylase deficiency. PLoS One. 2008; 3:e2138. [PubMed: 18478071]

11. Chen W, Xu Z, Sullivan A, et al. Junction site analysis of chimeric CYP21A1P/CYP21A2 genes in 21-hydroxylase deficiency. Clin Chem. 2012; 58:421. [PubMed: 22156666]

12. Parker EA, Hovanes K, Germak J, Porter F, Merke DP. Maternal 21-hydroxylase deficiency and uniparental isodisomy of chromosome 6 and $X$ results in a child with 21-hydroxylase deficiency and Klinefelter syndrome. Am J Med Genet A. 2006; 140:2236. [PubMed: 16906568]

13. Livadas S, Dracopoulou M, Dastamani A, et al. The spectrum of clinical, hormonal and molecular findings in 280 individuals with nonclassical congenital adrenal hyperplasia caused by mutations of the CYP21A2 gene. Clin Endocrinol (Oxf). 2015; 82:543. [PubMed: 25041270]

14. Speiser PW, Knochenhauer ES, Dewailly D, et al. A multicenter study of women with nonclassical congenital adrenal hyperplasia: relationship between genotype and phenotype. Mol Genet Metab. 2000; 71:527. [PubMed: 11073721]

15. Bidet M, Bellanne-Chantelot C, Galand-Portier MB, et al. Clinical and molecular characterization of a cohort of 161 unrelated women with nonclassical congenital adrenal hyperplasia due to 21hydroxylase deficiency and 330 family members. J Clin Endocrinol Metab. 2009; 94:1570. [PubMed: 19208730]

16. Barbaro M, Soardi FC, Ostberg LJ, et al. In vitro functional studies of rare CYP21A2 mutations and establishment of an activity gradient for nonclassic mutations improve phenotype predictions in congenital adrenal hyperplasia. Clin Endocrinol (Oxf). 2015; 82:37. [PubMed: 24953648]

17. Miller WL. Steroid hormone synthesis in mitochondria. Mol Cell Endocrinol. 2013; 379:62. [PubMed: 23628605]

18. Arlt W, Allolio B. Adrenal insufficiency. Lancet. 2003; 361:1881. [PubMed: 12788587]

19. White PC, Bachega TA. Congenital adrenal hyperplasia due to 21-hydroxylase deficiency: From birth to adulthood. Semin Reprod Med. 2012; 30:400. [PubMed: 23044877]

20. Mooij CF, Parajes S, Pijnenburg-Kleizen KJ, et al. Influence of 17-Hydroxyprogesterone, Progesterone and Sex Steroids on Mineralocorticoid Receptor Transactivation in Congenital Adrenal Hyperplasia. Horm Res Paediatr. 2015 (in press).

21. Merke DP, Chrousos GP, Eisenhofer G, et al. Adrenomedullary dysplasia and hypofunction in patients with classic 21-hydroxylase deficiency. N Engl J Med. 2000; 343:1362. [PubMed: 11070100]

22. Wilson JD, Auchus RJ, Leihy MW, et al. 5alpha-androstane-3alpha,17beta-diol is formed in tammar wallaby pouch young testes by a pathway involving 5alpha-pregnane-3alpha,17alphadiol-20-one as a key intermediate. Endocrinology. 2003; 144:575. [PubMed: 12538619]

23. Kamrath C, Hochberg Z, Hartmann MF, et al. Increased activation of the alternative "backdoor" pathway in patients with 21-hydroxylase deficiency: evidence from urinary steroid hormone analysis. J Clin Endocrinol Metab. 2012; 97:E367. [PubMed: 22170725]

24. Auchus RJ. The backdoor pathway to dihydrotestosterone. Trends Endocrinol Metab. 2004; 15:432. [PubMed: 15519890] 
25. Kamrath C, Hartmann MF, Wudy SA. Androgen synthesis in patients with congenital adrenal hyperplasia due to 21-hydroxylase deficiency. Horm Metab Res. 2013; 45:86. [PubMed: 23345132]

26. Turcu AF, Rege J, Chomic R, et al. Profiles of 21-Carbon Steroids in 21-hydroxylase Deficiency. J Clin Endocrinol Metab. 2015; 100:2283. [PubMed: 25850025]

27. Turcu AF, Nanba AT, Chomic R, et al. Adrenal-derived 11-Oxygenated 19-Carbon Steroids are the Dominant Androgens in Classic 21-Hydroxylase Deficiency. Eur J Endocrinol. 2016; 174:601. [PubMed: 26865584]

28. Storbeck KH, Bloem LM, Africander D, et al. 11ß-Hydroxy-dihydrotestosterone and 11ketodihydrotestosterone, novel C19 steroids with androgenic activity: a putative role in castration resistant prostate cancer? Mol Cell Endocrinol. 2013; 377:135. [PubMed: 23856005]

29. Lindert J, Hiort O, Tushaus L, et al. Perineal ultrasound offers useful information in girls with congenital adrenal hyperplasia. J Pediatr Urol. 2016 Sep 10. pii: S1477-5131(16)30241-8.

30. Moran C, Azziz R, Carmina E, et al. 21-hydroxylase-deficient nonclassic adrenal hyperplasia is a progressive disorder: a multicenter study. Am J Obstet Gynecol. 2000; 183:1468. [PubMed: 11120512]

31. Binay C, Simsek E, Cilingir O, Yuksel Z, Kutlay O, Artan S. Prevalence of nonclassic congenital adrenal hyperplasia in Turkish children presenting with premature pubarche, hirsutism, or oligomenorrhoea. Int J Endocrinol. 2014; 2014:768506. [PubMed: 24778650]

32. Armengaud JB, Charkaluk ML, Trivin C, et al. Precocious pubarche: distinguishing late-onset congenital adrenal hyperplasia from premature adrenarche. J Clin Endocrinol Metab. 2009; 94:2835. [PubMed: 19454583]

33. Moran C, Azziz R, Weintrob N, et al. Reproductive outcome of women with 21-hydroxylasedeficient nonclassic adrenal hyperplasia. J Clin Endocrinol Metab. 2006; 91:3451. [PubMed: 16822826]

34. Bidet M, Bellanne-Chantelot C, Galand-Portier MB, et al. Fertility in women with nonclassical congenital adrenal hyperplasia due to 21-hydroxylase deficiency. J Clin Endocrinol Metab. 2010; 95:1182. [PubMed: 20080854]

35. Huerta R, Dewailly D, Decanter C, et al. Adrenocortical hyperresponsivity to adrenocorticotropic hormone: a mechanism favoring the normal production of cortisol in 21-hydroxylase-deficient nonclassic adrenal hyperplasia. Fertil Steril. 2000; 74:329. [PubMed: 10927053]

36. Lobo RA, Goebelsmann U. Adult manifestation of congenital adrenal hyperplasia due to incomplete 21-hydroxylase deficiency mimicking polycystic ovarian disease. Am J Obstet Gynecol. 1980; 138:720. [PubMed: 6254362]

37. Pall M, Azziz R, Beires J, et al. The phenotype of hirsute women: a comparison of polycystic ovary syndrome and 21-hydroxylase-deficient nonclassic adrenal hyperplasia. Fertil Steril. 2010; 94:684. [PubMed: 19726039]

38. Escobar-Morreale HF, Sanchon R, San Millan JL. A prospective study of the prevalence of nonclassical congenital adrenal hyperplasia among women presenting with hyperandrogenic symptoms and signs. J Clin Endocrinol Metab. 2008; 93:527. [PubMed: 18000084]

39. Pignatelli D. Non-classic adrenal hyperplasia due to the deficiency of 21-hydroxylase and its relation to polycystic ovarian syndrome. Front Horm Res. 2013; 40:158. [PubMed: 24002412]

40. Oncul M, Sahmay S, Tuten A, et al. May AMH levels distinguish LOCAH from PCOS among hirsute women? Eur J Obstet Gynecol Reprod Biol. 2014; 178:183. [PubMed: 24792539]

41. Nandagopal R, Sinaii N, Avila NA, et al. Phenotypic profiling of parents with cryptic nonclassic congenital adrenal hyperplasia: findings in 145 unrelated families. Eur J Endocrinol. 2011; 164:977. [PubMed: 21444649]

42. Yildiz BO, Bolour S, Woods K, et al. Visually Scoring Hirsutism. Hum Reprod Update. 2010; 16:51. [PubMed: 19567450]

43. Ko JH, Huang YH, Kuo TT. Hair counts from normal scalp biopsy in Taiwan. Dermatol Surg. 2012; 38:1516. [PubMed: 22687262]

44. Martin KA, Chang RJ, Ehrmann DA, et al. Evaluation and Treatment of Hirsutism in Premenopausal Women: an Endocrine Society Clinical Practice Guideline. J Clin Endocrin Metab. 2008; 93:1105. 
45. Zhao X, Ni R, Li L, et al. Defining Hirsutism in Chinese Women: A Cross-Sectional Study. Fertil Steril. 2011; 96:792. [PubMed: 21762890]

46. DeUgarte CM, Woods KS, Bartolucci AA, Azziz R. Degree of facial and body terminal hair growth in unselected black and white women: toward a populational definition of hirsutism. J Clin Endocrinol Metab. 2006; 91:1345. [PubMed: 16449347]

47. O’Donovan C, Kusumakar V, Graves GR, et al. Menstrual abnormalities and polycystic ovary syndrome in women taking valproate for bipolar mood disorder. J Clin Psychiatry. 2002; 63:322. [PubMed: 12000206]

48. Nelson-DeGrave VL, Wickenheisser JK, Cockrell JE, et al. Valproate potentiates androgen biosynthesis in human ovarian theca cells. Endocrinology. 2004; 145:799. [PubMed: 14576182]

49. Ghizzoni L, Virdis R, Vottero A, et al. Pituitary-ovarian responses to leuprolide acetate testing in patients with congenital adrenal hyperplasia due to 21-hydroxylase deficiency. J Clin Endocrinol Metab. 1996; 81:601. [PubMed: 8636275]

50. Azziz R, Carmina E, Chen Z, et al. Polycystic ovary syndrome. Nat Rev Dis Primers. 2016; 2:16057.doi: 10.1038/nrdp.2016.57 [PubMed: 27510637]

51. Herbison AE. Control of puberty onset and fertility by gonadotropin-releasing hormone neurons. Nat Rev Endocrinol. 2016; 12:452. [PubMed: 27199290]

52. Zeleznik AJ. The physiology of follicle selection. Reprod Biol Endocrinol. 2004; 2:31. [PubMed: 15200680]

53. Nippoldt TB, Reame NE, Kelch RP, et al. The roles of estradiol and progesterone in decreasing luteinizing hormone pulse frequency in the luteal phase of the menstrual cycle. J Clin Endocrinol Metab. 1989; 69:67. [PubMed: 2499593]

54. Barnes RB, Rosenfield RL, Ehrmann DA, et al. Ovarian hyperandrogenism as a result of congenital adrenal virilizing disorders: evidence for perinatal masculinization of neuroendocrine function in women. J Clin Endocrinol Metab. 1994; 79:1328. [PubMed: 7962325]

55. Belgorosky A, Chahin S, Rivarola MA. Elevation of serum luteinizing hormone levels during hydrocortisone treatment in infant girls with 21-hydroxylase deficiency. Acta Paediatr. 1996; 85:1172. [PubMed: 8922078]

56. Roland AV, Moenter SM. Reproductive neuroendocrine dysfunction in polycystic ovary syndrome: insight from animal models. Front Neuroendocrinol. 2014; 35:494. [PubMed: 24747343]

57. Taylor AE, McCourt B, Martin KA, et al. Determinants of abnormal gonadotropin secretion in clinically defined women with polycystic ovary syndrome. J Clin Endocrinol Metab. 1997; 82:2248. [PubMed: 9215302]

58. McGee WK, Bishop CV, Bahar A, et al. Elevated androgens during puberty in female rhesus monkeys lead to increased neuronal drive to the reproductive axis: a possible component of polycystic ovary syndrome. Hum Reprod. 2012; 27:531. [PubMed: 22114112]

59. Levin JH, Carmina E, Lobo RA. Is the inappropriate gonadotropin secretion of patients with polycystic ovary syndrome similar to that of patients with adult-onset congenital adrenal hyperplasia? Fertil Steril. 1991; 56:635. [PubMed: 1915936]

60. Bachelot A, Chakhtoura Z, Plu-Bureau G, et al. CAHLH study group. Influence of hormonal control on LH pulsatility and secretion in women with classical congenital adrenal hyperplasia. Eur J Endocrinol. 2012; 167:499. [PubMed: 22893695]

61. Soules MR, Steiner RA, Clifton DK, et al. Progesterone modulation of pulsatile luteinizing hormone secretion in normal women. J Clin Endocrinol Metab. 1984; 58:378. [PubMed: 6420438]

62. Couzinet B, Young J, Kujas M, et al. The antigonadotropic activity of a 19-nor-progesterone derivative is exerted both at the hypothalamic and pituitary levels in women. J Clin Endocrinol Metab. 1999; 84:4191. [PubMed: 10566671]

63. Moenter SM. Leap of Faith: Does Serum Luteinizing Hormone Always Accurately Reflect Central Reproductive Neuroendocrine Activity? Neuroendocrinology. 2015; 102:256. [PubMed: 26278916]

64. Lucis OJ, Hobkirk R, Hollenberg CH, et al. Polycystic ovaries associated with congenital adrenal hyperplasia. Can Med Assoc J. 1966; 94:1. [PubMed: 5901591]

J Pediatr Adolesc Gynecol. Author manuscript; available in PMC 2018 October 01. 
65. Pache TD, Chadha S, Gooren LJ, et al. Ovarian morphology in long-term androgen-treated female to male transsexuals. A human model for the study of polycystic ovarian syndrome? Histopathology. 1991; 19:445. [PubMed: 1757084]

66. Sen A, Hammes SR. Granulosa cell-specific androgen receptors are critical regulators of ovarian development and function. Mol Endocrinol. 2010; 24:1393. [PubMed: 20501640]

67. Walters KA. Role of androgens in normal and pathological ovarian function. Reproduction. 2015; 149:R193. [PubMed: 25516989]

68. Gleicher N, Weghofer A, Barad DH. The role of androgens in follicle maturation and ovulation induction: friend or foe of infertility treatment? Reprod Biol Endocrinol. 2011; 9:116. [PubMed: 21849061]

69. Lebbe M, Woodruff TK. Involvement of androgens in ovarian health and disease. Mol Hum Reprod. 2013; 19:828. [PubMed: 24026057]

70. O'Driscoll JB, Anderson DC. Untreated congenital adrenal hyperplasia presenting with severe androgenic alopecia. J R Soc Med. 1993; 86:229. [PubMed: 8505734]

71. Auchus RJ. Steroid assays and endocrinology: best practices for basic scientists. Endocrinology. 2014; 155:2049. [PubMed: 24837046]

72. Krone N, Hughes BA, Lavery GG, et al. Gas chromatography/mass spectrometry (GC/MS) remains a pre-eminent discovery tool in clinical steroid investigations even in the era of fast liquid chromatography tandem mass spectrometry (LC/MS/MS). J Steroid Biochem Mol Biol. 2010; 121:496. [PubMed: 20417277]

73. Witchel SF, Nayak S, Suda-Hartman M, et al. Newborn screening for 21-hydroxylase deficiency: results of CYP21 molecular genetic analysis. J Pediatr. 1997; 131:328. [PubMed: 9290628]

74. Escobar-Morreale HF, Sanchon R, San Millan JL. A prospective study of the prevalence of nonclassical congenital adrenal hyperplasia among women presenting with hyperandrogenic symptoms and signs. J Clin Endocrinol Metab. 2008; 93:527. [PubMed: 18000084]

75. Groschl M, Rauh M, Schmid P, et al. Relationship between salivary progesterone, 17hydroxyprogesterone, and cortisol levels throughout the normal menstrual cycle of healthy postmenarcheal girls. Fertil Steril. 2001; 76:615. [PubMed: 11532491]

76. Speckart PF, Nicoloff JT, Bethune JE. Screening for adrenocortical insufficiency with cosyntropin (synthetic ACTH). Archives of Internal Medicine. 1971; 128:761. [PubMed: 4330323]

77. Grinspoon SK, Biller BM. Clinical review 62: Laboratory assessment of adrenal insufficiency. J Clin Endocrinol Metab. 1994; 79:923. [PubMed: 7962298]

78. Trapp CM, Speiser PW, Oberfield SE. Congenital adrenal hyperplasia: an update in children. Curr Opin Endocrinol Diabetes Obes. 2011; 18:166. [PubMed: 21494138]

79. Deneux C, Tardy V, Dib A, et al. Phenotype-genotype correlation in 56 women with nonclassical congenital adrenal hyperplasia due to 21-hydroxylase deficiency. J Clin Endocrinol Metab. 2001; 86:207. [PubMed: 11232002]

80. Fiet J, Gueux B, Gourmelen M, et al. Comparison of basal and adrenocorticotropin-stimulated plasma 21-deoxycortisol and 17-hydroxyprogesterone values as biological markers of late-onset adrenal hyperplasia. J Clin Endocrinol Metab. 1988; 66:659. [PubMed: 2831244]

81. Stikkelbroeck NM, Hoefsloot LH, de Wijs IJ, et al. CYP21 gene mutation analysis in 198 patients with 21-hydroxylase deficiency in The Netherlands: six novel mutations and a specific cluster of four mutations. J Clin Endocrinol Metab. 2003; 88:3852. [PubMed: 12915679]

82. Parajes S, Quinteiro C, Dominguez F, et al. High frequency of copy number variations and sequence variants at CYP21A2 locus: implication for the genetic diagnosis of 21-hydroxylase deficiency. PLoS One. 2008; 3(5):e2138. [PubMed: 18478071]

83. Xu Z, Chen W, Merke DP, et al. Comprehensive mutation analysis of the CYP21A2 gene: an efficient multistep approach to the molecular diagnosis of congenital adrenal hyperplasia. J Mol Diagn. 2013; 15:745. [PubMed: 24071710]

84. Nordenstrom A, Thilen A, Hagenfeldt L, et al. Genotyping is a valuable diagnostic complement to neonatal screening for congenital adrenal hyperplasia due to steroid 21-hydroxylase deficiency. $\mathrm{J}$ Clin Endocrinol Metab. 1999; 84:1505. [PubMed: 10323369] 
85. New MI, Tong YK, Yuen T, et al. Noninvasive prenatal diagnosis of congenital adrenal hyperplasia using cell-free fetal DNA in maternal plasma. J Clin Endocrinol Metab. 2014; 99:E1022. [PubMed: 24606108]

86. Witchel SF, Lee PA. Identification of heterozygotic carriers of 21-hydroxylase deficiency: sensitivity of ACTH stimulation tests. Am J Med Genet. 1998; 76:337. [PubMed: 9545098]

87. Pang S, Hotchkiss J, Drash AL, et al. Microfilter paper method for 17 alpha-hydroxyprogesterone radioimmunoassay: its application for rapid screening for congenital adrenal hyperplasia. J Clin Endocrinol Metab. 1977; 45:1003. [PubMed: 925125]

88. Heather NL, Seneviratne SN, Webster D, et al. Newborn screening for congenital adrenal hyperplasia in New Zealand, 1994-2013. J Clin Endocrinol Metab. 2015; 100:1002. [PubMed: 25494862]

89. Hayashi GY, Carvalho DF, de Miranda MC, et al. Neonatal 17-hydroxyprogesterone levels adjusted according to age at sample collection and birthweight improve the efficacy of congenital adrenal hyperplasia newborn screening. Clin Endocrinol (Oxf). 2017; 86:480. [PubMed: 27978607]

90. Kamrath C, Hartmann MF, Boettcher C, et al. Reduced activity of $11 \beta$-hydroxylase accounts for elevated 17a-hydroxyprogesterone in preterms. J Pediatr. 2014; 165:280. [PubMed: 24862381]

91. Pearce M, DeMartino L, McMahon R, et al. Newborn screening for congenital adrenal hyperplasia in New York State. Mol Genet Metab Rep. 2016; 7:1. [PubMed: 27331001]

92. Gidlof S, Falhammar H, Thilen A, et al. One hundred years of congenital adrenal hyperplasia in Sweden: a retrospective, population-based cohort study. Lancet Diabetes Endocrinol. 2013; 1:35. [PubMed: 24622265]

93. Sarafoglou K, Banks K, Kyllo J, et al. Cases of congenital adrenal hyperplasia missed by newborn screening in Minnesota. JAMA. 2012; 307:2371. [PubMed: 22692165]

94. Varness TS, Allen DB, Hoffman GL. Newborn screening for congenital adrenal hyperplasia has reduced sensitivity in girls. J Pediatr. 2005; 147:493. [PubMed: 16227036]

95. Sarafoglou K, Banks K, Gaviglio A, et al. Comparison of one-tier and two-tier newborn screening metrics for congenital adrenal hyperplasia. Pediatrics. 2012; 130:e1261. [PubMed: 23071209]

96. Chan CL, McFann K, Taylor L, et al. Congenital adrenal hyperplasia and the second newborn screen. J Pediatr. 2013; 163:109. [PubMed: 23414665]

97. Center NNSaGR. San Antonio: Department of Pediatrics, University of Texas Health Science Center at San Antonio; 2011. Available at: http://genes-r-us.uthscsa.edu/ [Accessed May 30, 2011]

98. Carmina E, Dewailly D, Escobar-Morreale HF, et al. Non-classic congenital adrenal hyperplasia due to 21-hydroxylase deficiency revisited: An update with a special focus on adolescent and adult women. Hum Reproduction Update. (in press).

99. Witchel SF. The medical home concept and congenital adrenal hyperplasia: a comfortable habitat! Int J Pediatr Endocrinol. 2010; 2010:561526. [PubMed: 20628559]

100. Azziz R, Slayden SM. The 21-hydroxylase-deficient adrenal hyperplasias: more than ACTH oversecretion. J Soc Gynecol Investig. 1996; 3:297.

101. Rezvani I, Garibaldi LR, Digeorge AM, et al. Disproportionate suppression of dehydroepiandrosterone sulfate (DHEAS) in treated patients with congenital adrenal hyperplasia due to 21-hydroxylase deficiency. Pediatr Res. 1983; 17:131. [PubMed: 6219334]

102. Muthusamy K, Elamin MB, Smushkin G, et al. Clinical review: Adult height in patients with congenital adrenal hyperplasia: a systematic review and metaanalysis. J Clin Endocrinol Metab. 2010; 95:4161. [PubMed: 20823467]

103. Auchus RJ. Management considerations for the adult with congenital adrenal hyperplasia. Mol Cell Endocrinol. 2015; 408:190. [PubMed: 25643980]

104. Stoupa A, Gonzalez-Briceno L, Pinto G, et al. Inadequate cortisol response to the tetracosactide (SynacthenR) test in non-classic congenital adrenal hyperplasia: an exception to the rule? Horm Res Paediatr. 2015; 83:262. [PubMed: 25677445]

105. Hindmarsh PC, Charmandari E. Variation in absorption and half-life of hydrocortisone influence plasma cortisol concentrations. Clin Endocrinol (Oxf). 2015; 82:557. [PubMed: 25369980]

106. Mallappa A, Sinaii N, Kumar P, et al. A phase 2 study of Chronocort, a modified-release formulation of hydrocortisone, in the treatment of adults with classic congenital adrenal hyperplasia. J Clin Endocrinol Metab. 2015; 100:1137. [PubMed: 25494662] 
107. Hindmarsh PC. The child with difficult to control Congenital Adrenal Hyperplasia: is there a place for continuous subcutaneous hydrocortisone therapy. Clin Endocrinol (Oxf). 2014; 81:15. [PubMed: 24655023]

108. Auchus RJ, Buschur EO, Chang AY, et al. Abiraterone acetate to lower androgens in women with classic 21-hydroxylase deficiency. J Clin Endocrinol Metab. 2014; 99:2763. [PubMed: 24780050]

109. Charmandari E, Hindmarsh PC, Johnston A, et al. Congenital adrenal hyperplasia due to 21hydroxylase deficiency: alterations in cortisol pharmacokinetics at puberty. J Clin Endocrinol Metab. 2001; 86:2701. [PubMed: 11397874]

110. Charmandari E, Brook CG, Hindmarsh PC. Classic congenital adrenal hyperplasia and puberty. Eur J Endocrinol. 2004; 151(Suppl 3):U77. [PubMed: 15554890]

111. Amies Oelschlager AM, Muscarella M, Gomez-Lobo V. Transition to Adult Care in Persons With Disorders of Sexual Development: The Role of the Gynecologist. Obstet Gynecol. 2015; 126:845. [PubMed: 26348185]

112. Engberg H, Moller A, Hagenfeldt K, et al. The experience of women living with Congenital Adrenal Hyperplasia: impact of the condition and the care given. Clin Endocrinol (Oxf). 2016; 85:21. [PubMed: 26941069]

113. Merke DP, Poppas DP. Management of adolescents with congenital adrenal hyperplasia. Lancet Diabetes Endocrinol. 2013; 1:341. [PubMed: 24622419]

114. Gastaud F, Bouvattier C, Duranteau L, et al. Impaired sexual and reproductive outcomes in women with classical forms of congenital adrenal hyperplasia. J Clin Endocrinol Metab. 2007; 92:1391. [PubMed: 17284631]

115. Pasterski V, Zucker KJ, Hindmarsh PC, et al. Increased Cross-Gender Identification Independent of Gender Role Behavior in Girls with Congenital Adrenal Hyperplasia: Results from a Standardized Assessment of 4- to 11-Year-Old Children. Arch Sex Behav. 2015; 44:1363. [PubMed: 25239661]

116. Frisen L, Nordenstrom A, Falhammar H, et al. Gender role behavior, sexuality, and psychosocial adaptation in women with congenital adrenal hyperplasia due to CYP21A2 deficiency. J Clin Endocrinol Metab. 2009; 94:3432. [PubMed: 19567521]

117. Hagenfeldt K, Janson PO, Holmdahl G, et al. Fertility and pregnancy outcome in women with congenital adrenal hyperplasia due to 21-hydroxylase deficiency. Hum Reprod. 2008; 23:1607. [PubMed: 18420648]

118. Crouch NS, Liao LM, Woodhouse CR, et al. Sexual function and genital sensitivity following feminizing genitoplasty for congenital adrenal hyperplasia. J Urol. 2008; 179:634. [PubMed: 18082214]

119. Nordenskjold A, Holmdahl G, Frisen L, et al. Type of mutation and surgical procedure affect long-term quality of life for women with congenital adrenal hyperplasia. J Clin Endocrinol Metab. 2008; 93:380. [PubMed: 18029470]

120. Braga LH, Pippi Salle JL. Congenital adrenal hyperplasia: a critical appraisal of the evolution of feminizing genitoplasty and the controversies surrounding gender reassignment. Euro J Pediatr Surg. 2009; 19:203.

121. Mouriquand PD, Gorduza DB, Gay CL, et al. Surgery in disorders of sex development (DSD) with a gender issue: If (why), when, and how? J Pediatr Urol. 2016; 12:139. [PubMed: 27132944]

122. Khattab A, Yau M, Qamar A, et al. Long term outcomes in 46, XX adult patients with congenital adrenal hyperplasia reared as males. J Steroid Biochem Mol Biol. 2017; 165(Pt A):12. [PubMed: 27125449]

123. Reichman DE, White PC, New MI, et al. Fertility in patients with congenital adrenal hyperplasia. Fertil Steril. 2014 Feb.101:301. [PubMed: 24355046]

124. Mulaikal RM, Migeon CJ, Rock JA. Fertility rates in female patients with congenital adrenal hyperplasia due to 21-hydroxylase deficiency. N Engl J Med. 1987; 316:178. [PubMed: 3491959]

125. Casteras A, De Silva P, Rumsby G, et al. Reassessing fecundity in women with classical congenital adrenal hyperplasia $(\mathrm{CAH})$ : normal pregnancy rate but reduced fertility rate. Clin Endocrinol. 2009; 70:833. 
126. Bouvattier C, Esterle L, Renoult-Pierre P, et al. Clinical Outcome, Hormonal Status, Gonadotrope Axis, and Testicular Function in 219 Adult Men Born With Classic 21-Hydroxylase Deficiency. A French National Survey. J Clin Endocrinol Metab. 2015; 100:2303. [PubMed: 25822101]

127. King TF, Lee MC, Williamson EE, et al. Experience in optimizing fertility outcomes in men with congenital adrenal hyperplasia due to 21 hydroxylase deficiency. Clin Endocrinol (Oxf). 2016; 84:830. [PubMed: 26666213]

128. Labarta E, Martinez-Conejero JA, Alama P, et al. Endometrial receptivity is affected in women with high circulating progesterone levels at the end of the follicular phase: a functional genomics analysis. Hum Reprod. 2011; 26:1813. [PubMed: 21540246]

129. Witchel SF. Management of CAH during pregnancy: optimizing outcomes. Curr Opin Endocrinol Diabetes Obes. 2012; 19:489. [PubMed: 23108200]

130. Nimkarn S, New MI. Prenatal diagnosis and treatment of congenital adrenal hyperplasia. Horm Res. 2007; 67:53. [PubMed: 17047340]

131. Goto M, Piper Hanley K, Marcos J, et al. In humans, early cortisol biosynthesis provides a mechanism to safeguard female sexual development. J Clin Invest. 2006; 116:953. [PubMed: 16585961]

132. Lo JC, Schwitzgebel VM, Tyrrell JB, et al. Normal female infants born of mothers with classic congenital adrenal hyperplasia due to 21-hydroxylase deficiency. J Clin Endocrinol Metab. 1999; 84:930. [PubMed: 10084573]

133. Carlson AD, Obeid JS, Kanellopoulou N, et al. Congenital adrenal hyperplasia: update on prenatal diagnosis and treatment. J Steroid Biochem Mol Biol. 1999; 69:19. [PubMed: 10418977]

134. New MI, Tong YK, Yuen T, et al. Noninvasive prenatal diagnosis of congenital adrenal hyperplasia using cell-free fetal DNA in maternal plasma. J Clin Endocrinol Metab. 2014; 99:E1022. [PubMed: 24606108]

135. Altarescu G. Prevention is the Best Therapy: The Geneticist's Approach. Pediatr Endocrinol Rev. 2016; 13(Suppl 1):649. [PubMed: 27491212]

136. New MI, Carlson A, Obeid J, et al. Extensive personal experience: Prenatal diagnosis for congenital adrenal hyperplasia in 532 pregnancies. J Clin Endocrinol Metab. 2001; 86:5651. [PubMed: 11739415]

137. Davis EP, Sandman CA, Buss C, et al. Fetal glucocorticoid exposure is associated with preadolescent brain development. Biol Psychiatry. 2013; 74:647. [PubMed: 23611262]

138. Lajic S, Nordenstrom A, Hirvikoski T. Long-term outcome of prenatal dexamethasone treatment of 21-hydroxylase deficiency. Endocr Dev. 2011; 20:96. [PubMed: 21164263]

139. Wallensteen L, Zimmermann M, Thomsen Sandberg MS, et al. Sex-Dimorphic Effects of Prenatal Treatment With Dexamethasone. J Clin Endocrinol Metab. 2016; 101:3838. [PubMed: 27482827]

140. Miller WL, Witchel SF. Prenatal treatment of congenital adrenal hyperplasia: risks outweigh benefits. Am J Obstet Gynecol. 2013; 208:354. [PubMed: 23123167]

141. Peffer ME, Zhang JY, Umfrey L, et al. Minireview: the impact of antenatal therapeutic synthetic glucocorticoids on the developing fetal brain. Mol Endocrinol. 2015; 29:658. [PubMed: 25763611]

142. Speiser PW, Azziz R, Baskin LS, et al. Endocrine Society. Congenital adrenal hyperplasia due to steroid 21-hydroxylase deficiency: an Endocrine Society clinical practice guideline. J Clin Endocrinol Metab. 2010; 95:4133. [PubMed: 20823466]

143. Arlt W, Willis DS, Wild SH, et al. United Kingdom Congenital Adrenal Hyperplasia Adult Study Executive (CaHASE). Health status of adults with congenital adrenal hyperplasia: a cohort study of 203 patients. J Clin Endocrinol Metab. 2010; 95:5110. [PubMed: 20719839]

144. Finkielstain GP, Kim MS, Sinaii N, et al. Clinical characteristics of a cohort of 244 patients with congenital adrenal hyperplasia. J Clin Endocrinol Metab. 2012; 97:4429. [PubMed: 22990093]

145. Krone N, Rose IT, Willis DS, et al. United Kingdom Congenital adrenal Hyperplasia Adult Study Executive (CaHASE). Genotype-phenotype correlation in 153 adult patients with congenital adrenal hyperplasia due to 21-hydroxylase deficiency: analysis of the United Kingdom 
Congenital adrenal Hyperplasia Adult Study Executive (CaHASE) cohort. J Clin Endocrinol Metab. 2013; 98:E346. [PubMed: 23337727]

146. Falhammar H, Filipsson H, Holmdahl G, et al. Metabolic profile and body composition in adult women with congenital adrenal hyperplasia due to 21-hydroxylase deficiency. J Clin Endocrinol Metab. 2007; 92:110. [PubMed: 17032717]

147. Falhammar H, Filipsson Nystrom H, Wedell A, et al. Cardiovascular risk, metabolic profile, and body composition in adult males with congenital adrenal hyperplasia due to 21-hydroxylase deficiency. Eur J Endocrinol. 2011; 164:285. [PubMed: 21098686]

148. Akyurek N, Atabek ME, Eklioğlu BS, et al. Ambulatory blood pressure and subclinical cardiovascular disease in patients with congenital adrenal hyperplasia: a preliminary report. $\mathrm{J}$ Clin Res Pediatr Endocrinol. 2015; 7:13. [PubMed: 25800471]

149. Bachelot A, Golmard JL, Dulon J, et al. Determining clinical and biological indicators for health outcomes in adult patients with childhood onset of congenital adrenal hyperplasia. Eur J Endocrinol. 2015; 173:175. [PubMed: 25947139]

150. Engberg H, Butwicka A, Nordenstrom A, et al. Congenital adrenal hyperplasia and risk for psychiatric disorders in girls and women born between 1915 and 2010: A total population study. Psychoneuroendocrinology. 2015; 60:195. [PubMed: 26184920]

151. Pescovitz OH, Comite F, Cassorla F, et al. True precocious puberty complicating congenital adrenal hyperplasia: treatment with a luteinizing hormone-releasing hormone analog. J Clin Endocrinol Metab. 1984; 58:857. [PubMed: 6368580]

152. Dacou-Voutetakis C, Karidis N. Congenital adrenal hyperplasia complicated by central precocious puberty: treatment with LHRH-agonist analogue. Ann N Y Acad Sci. 1993; 687:250. [PubMed: 8323180]

153. Guven A, Nurcan Cebeci A, Hancili S. Gonadotropin releasing hormone analog treatment in children with congenital adrenal hyperplasia complicated by central precocious puberty. Hormones (Athens). 2015; 14:265. [PubMed: 25553759]

154. Canalis E, Mazziotti G, Giustina A, et al. Glucocorticoid-induced osteoporosis: pathophysiology and therapy. Osteoporos Int. 2007; 18:1319. [PubMed: 17566815]

155. Ventura A, Brunetti G, Colucci S, et al. Glucocorticoid-induced osteoporosis in children with 21hydroxylase deficiency. Biomed Res Int. 2013; 2013:250462. [PubMed: 23484098]

156. Falhammar H, Filipsson Nystrom H, Wedell A, et al. Bone mineral density, bone markers, and fractures in adult males with congenital adrenal hyperplasia. Eur J Endocrinol. 2013; 168:331. [PubMed: 23211577]

157. Zemel BS, Leonard MB, Kelly A, et al. Height adjustment in assessing dual energy x-ray absorptiometry measurements of bone mass and density in children. J Clin Endocrinol Metab. 2010; 95:1265. [PubMed: 20103654]

158. Kim MS, Ryabets-Lienhard A, Bali B, et al. Decreased adrenomedullary function in infants with classical congenital adrenal hyperplasia. J Clin Endocrinol Metab. 2014; 99:E1597. [PubMed: 24878051]

159. Claahsen-van der Grinten HL, Dehzad F, Kamphuis-van Ulzen K, et al. Increased prevalence of testicular adrenal rest tumours during adolescence in congenital adrenal hyperplasia. Horm Res Paediatr. 2014; 82:238. [PubMed: 25195868]

160. Falhammar H, Nystrom HF, Ekstrom U, et al. Fertility, sexuality and testicular adrenal rest tumors in adult males with congenital adrenal hyperplasia. Eur J Endocrinol. 2012; 166:441. [PubMed: 22157069]

161. Reisch N, Rottenkolber M, Greifenstein A, et al. Testicular adrenal rest tumors develop independently of long-term disease control: a longitudinal analysis of 50 adult men with congenital adrenal hyperplasia due to classic 21-hydroxylase deficiency. J Clin Endocrinol Metab. 2013; 98:E1820. [PubMed: 23969190]

162. Chen HD, Huang LE, Zhong ZH, et al. Ovarian Adrenal Rest Tumors Undetected by Imaging Studies and Identified at Surgery in Three Females with Congenital Adrenal Hyperplasia Unresponsive to Increased Hormone Therapy Dosage. Endocr Pathol. 2016 Dec 28.

163. McGeoch SC, Olson S, Krukowski ZH, et al. Giant bilateral myelolipomas in a man with congenital adrenal hyperplasia. J Clin Endocrinol Metab. 2012; 97:343. [PubMed: 22238394] 
164. Dhir V, Ivison HE, Krone N, et al. Differential inhibition of CYP17A1 and CYP21A2 activities by the P450 oxidoreductase mutant A287P. Mol Endocrinol. 2007; 21:1958. [PubMed: 17505056]

165. Idkowiak J, O'Riordan S, Reisch N, et al. Pubertal presentation in seven patients with congenital adrenal hyperplasia due to P450 oxidoreductase deficiency. J Clin Endocrinol Metab. 2011; 96:E453. [PubMed: 21190981]

166. Krone N, Reisch N, Idkowiak J, et al. Genotype-phenotype analysis in congenital adrenal hyperplasia due to P450 oxidoreductase deficiency. J Clin Endocrinol Metab. 2012; 97:E257. [PubMed: 22162478]

167. Hershkovitz E, Parvari R, Wudy SA, et al. Homozygous mutation G539R in the gene for P450 oxidoreductase in a family previously diagnosed as having 17,20-lyase deficiency. J Clin Endocrinol Metab. 2008; 93:3584. [PubMed: 18559916]

168. Shackleton C, Marcos J, Malunowicz EM, et al. Biochemical diagnosis of Antley-Bixler syndrome by steroid analysis. Am J Med Genet. 2004; 128A:223. [PubMed: 15216541]

169. Sahakitrungruang T, Huang N, Tee MK, et al. Clinical, Genetic, and Enzymatic Characterization of P450 Oxidoreductase Deficiency in Four Patients. J Clinical Endocrinol Metabol. 2009; 94:4992.

170. Miller WL, Auchus RJ. The molecular biology, biochemistry, and physiology of human steroidogenesis and its disorders. Endocr Rev. 2011; 32:81. [PubMed: 21051590]

171. Mooij CF, Parajes S, Rose IT, et al. Characterization of the molecular genetic pathology in patients with 11 $\beta$-hydroxylase deficiency. Clin Endocrinol (Oxf). 2015; 83:629. [PubMed: 26053152]

172. Khoury K, Barbar E, Ainmelk Y, et al. Thirty-Eight-Year Follow-Up of Two Sibling Lipoid Congenital Adrenal Hyperplasia Patients Due to Homozygous Steroidogenic Acute Regulatory (STARD1) Protein Mutation. Molecular Structure and Modeling of the STARD1 L275P Mutation. Front Neurosci. 2016; 10:527. [PubMed: 27917104]

173. Baker BY, Lin L, Kim CJ, et al. Nonclassic congenital lipoid adrenal hyperplasia: a new disorder of the steroidogenic acute regulatory protein with very late presentation and normal male genitalia. J Clin Endocrinol Metab. 2006; 91:4781. [PubMed: 16968793]

174. Tee MK, Abramsohn M, Loewenthal N, et al. Varied clinical presentations of seven patients with mutations in CYP11A1 encoding the cholesterol side-chain cleavage enzyme, P450scc. J Clin Endocrinol Metab. 2013; 98:713. [PubMed: 23337730]

175. Carvalho LC, Brito VN, Martin RM, et al. Clinical, hormonal, ovarian, and genetic aspects of 46, XX patients with congenital adrenal hyperplasia due to CYP17A1 defects. Fertil Steril. 2016; 105:1612. [PubMed: 26920256]

176. Jones CM, Mallappa A, Reisch N, et al. Modified release and conventional glucocorticoids and diurnal androgen excretion in congenital adrenal hyperplasia. J Clin Endocrinol Metab. 2016 Nov 15.:jc20162855. (in press).

177. Bell LE, Bartosh SM, Davis CL, et al. Adolescent Transition to Adult Care in Solid Organ Transplantation: a consensus conference report. Am J Transplant. 2008; 8:2230. [PubMed: 18822088] 


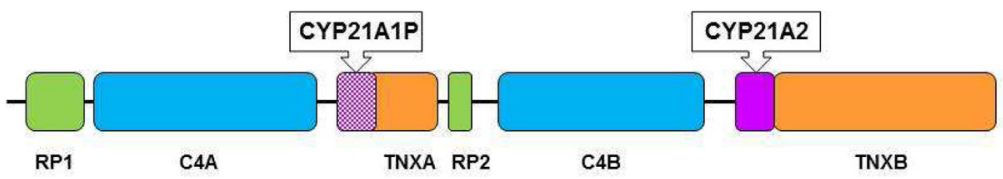

Figure 1.

Cartoon of RCCX unit gene. Flanking genes, $C Y P 21 A 2$, and $C Y P 21 A 1 P$ are located in the class III region of the MHC on chromosome 6p21.3. RP1 encodes a nuclear threonine/serine protein kinase. $C 4 A$ (Rodgers blood group) and $C 4 B$ (Chido blood group) encode functional complement 4. TNXB encodes tenascin, an extracellular protein. TNXA is the deleted form of $T N X B$ and encodes a pseudogene. $R P 2$ is the truncated form of $R P 1$. 


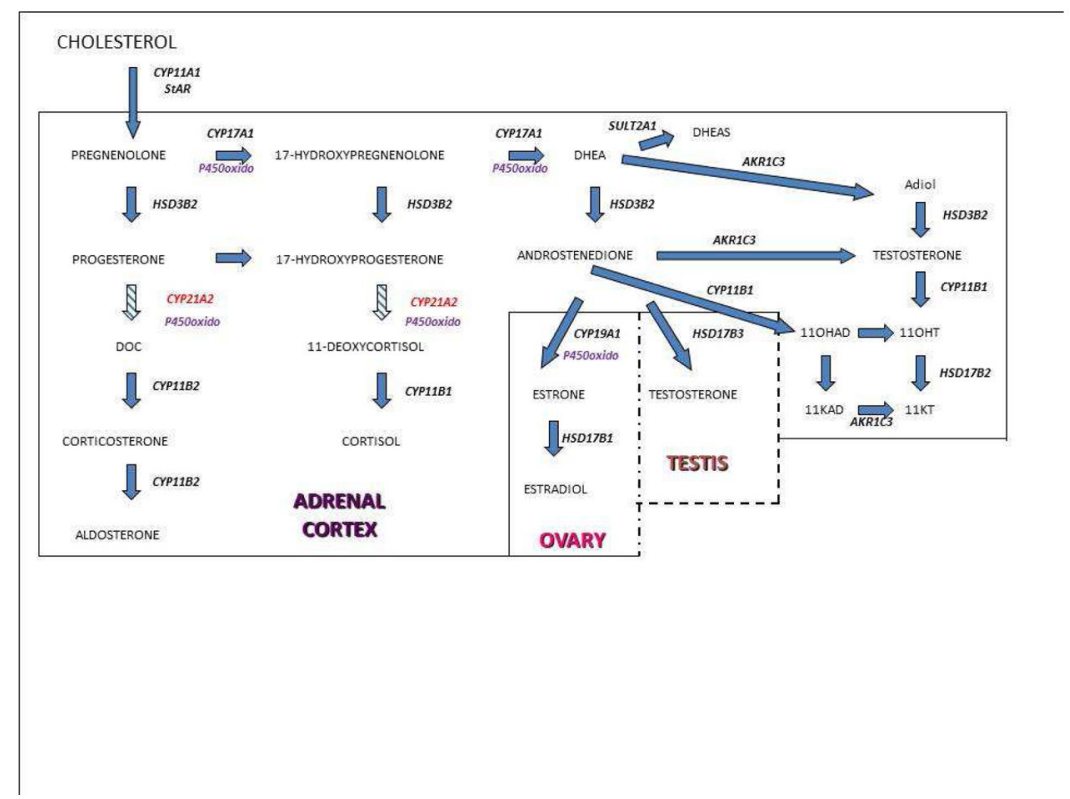

Figure 2.

Pathways of steroid hormone synthesis. Key: StAR, steroidogeneic acute regulatory protein; CYP11A1, cholesterol desmolase; CYP21A2, 21-hydroxylase; HSD3B2, 3 $\beta$-hydroxysteroid dehydrogenase; CYP11B1, 11ß-hydroxylase; CYP11B2, aldosterone synthase; CYP17A1, 17a-hydroxyase/17,20-lyase; P450, P450 oxidoreductase; AKR1C3, 17ß-hydroxysteroid dehydrogenase type 5; SULT2A1, steroid sulfotransferase 2A1; DOC, 11deoxycorticosterone; 11OHAD, 11-hydroxyandrostenedione; Adiol, 5-androstendiol; $11 \mathrm{KAD}, 11$-ketoandrostenedione; 11OHT, 11-hydroxytestosterone; 11KT, 11ketotestosterone. 


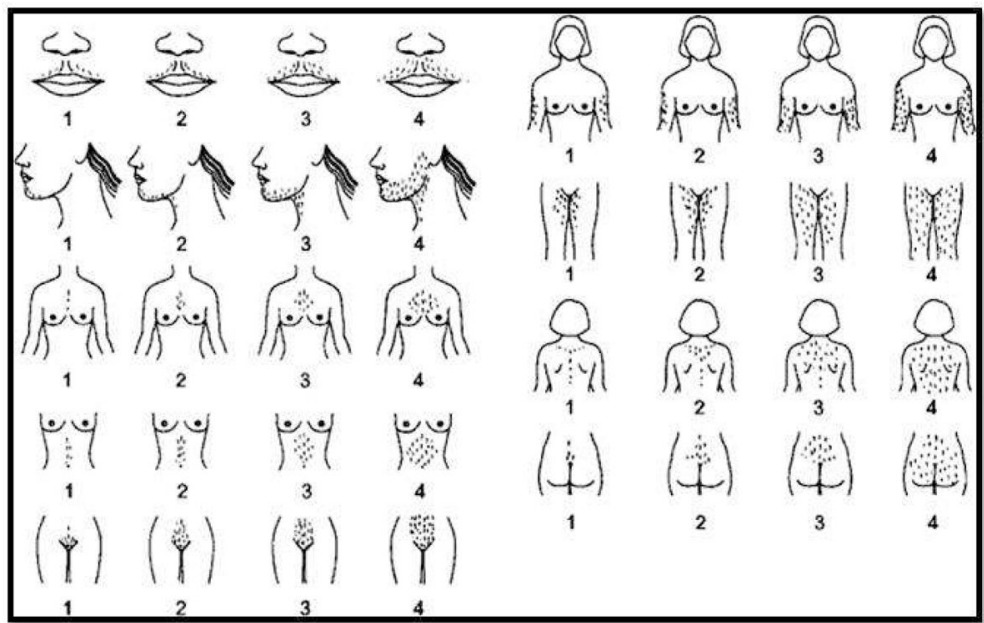

Figure 3.

Modified Ferriman-Gallwey Scoring System. This semi-objective scoring system is based on observation of nine body areas including upper lip, chin, chest, arm, upper abdomen, lower abdomen, upper back, lower back, and thighs. The areas are scored from 1 (minimal terminal hairs present) to 4 (equivalent to a hairy man). If no terminal hairs are noted in the specific body area being examined the score is zero. Clinically terminal hair hairs can be distinguished from vellus hairs primarily by their length (i.e. greater than $0.5 \mathrm{~cm}$ ) and the fact that they are usually pigmented (reprinted with kind permission of Ricardo Azziz, copyright 1997) 


\section{Table 1}

Checklist for transition ${ }^{177}$

- $\quad$ Ability to describe and discuss disorder (knowledge)

- Awareness of implications of disorder on overall health

- Comprehension on sexuality and reproductive health

- $\quad$ Fertility/infertility aspects

- $\quad$ Genetic counseling, if relevant

- $\quad$ Risk for STDs

- Responsibility for own healthcare

- $\quad$ Knowledge of meds, doses, etc

- $\quad$ Able to order refills and schedule appointments

- $\quad$ Know when to seek emergency healthcare

- $\quad$ Understand medical insurance coverage

- Able to function independently

- Ownership of personal medical information (folder, EMR)

- $\quad$ Expresses readiness for transition 